\title{
CKIP-1 regulates macrophage proliferation by inhibiting TRAF6-mediated Akt activation
}

Luo Zhang ${ }^{1,3, *}$, Yiwu Wang ${ }^{1, *}$, Fengjun Xiao ${ }^{4}$, Shaoxia Wang ${ }^{5}$, Guichun Xing ${ }^{1}$, Yang Li $^{5}$, Xiushan Yin ${ }^{1}$, Kefeng Lu ${ }^{1}$, Rongfei Wei ${ }^{1}$, Jiao Fan ${ }^{1}$, Yuhan Chen ${ }^{1}$, Tao Li ${ }^{6}$, Ping Xie ${ }^{1}$, Lin Yuan ${ }^{1}$, Lei Song ${ }^{1}$, Lanzhi Ma Lujing Ding ${ }^{7}$, Fuchu $\mathrm{He}^{1}$, Lingqiang Zhang ${ }^{1,2}$

${ }^{\text {I}}$ State Key Laboratory of Proteomics, Beijing Proteome Research Center, Beijing Institute of Radiation Medicine, Collaborative Innovation Center for Cancer Medicine, Beijing, China; ${ }^{2}$ Institute of Cancer Stem Cell, Dalian Medical University, Dalian, Liaoning 116044, China; ${ }^{3}$ Department of Biomedical Engineering, Chinese PLA 307 Hospital, Beijing, China; ${ }^{4}$ Department of Experimental Hematology, Beijing Institute of Radiation Medicine, Beijing, China; ${ }^{5}$ Department of Experimental Pathology, Beijing Institute of Radiation Medicine, Beijing, China; ${ }^{6}$ Institute of Basic Medical Sciences, China National Center of Biomedical Analysis, Beijing, China; ${ }^{7}$ Laboratory Animal Center of the Academy of Military Medical Sciences, Beijing, China

Macrophages play pivotal roles in development, homeostasis, tissue repair and immunity. Macrophage proliferation is promoted by macrophage colony-stimulating factor (M-CSF)-induced Akt signaling; yet, how this process is terminated remains unclear. Here, we identify casein kinase 2-interacting protein-1 (CKIP-1) as a novel inhibitor of macrophage proliferation. In resting macrophages, CKIP-1 was phosphorylated at Serine 342 by constitutively active GSK3 $\beta$, the downstream target of Akt. This phosphorylation triggers the polyubiquitination and proteasomal degradation of CKIP-1. Upon M-CSF stimulation, Akt is activated by CSF-1R-PI3K and then inactivates GSK3ß, leading to the stabilization of CKIP-1 and $\beta$-catenin proteins. $\beta$-catenin promotes the expression of proliferation genes including cyclin D and c-Myc. CKIP-1 interacts with TRAF6, a ubiquitin ligase required for K63-linked ubiquitination and plasma membrane recruitment of Akt, and terminates TRAF6-mediated Akt activation. By this means, CKIP-1 inhibits macrophage proliferation specifically at the late stage after M-CSF stimulation. Furthermore, CKIP-1 deficiency results in increased proliferation and decreased apoptosis of macrophages in vitro and $C K I P-1^{-/}$mice spontaneously develop a macrophage-dominated splenomegaly and myeloproliferation. Together, these data demonstrate that CKIP-1 plays a critical role in the regulation of macrophage homeostasis by inhibiting TRAF6-mediated Akt activation.

Keywords: macrophage proliferation; Akt signaling; TRAF6; GSK3 $\beta$; CKIP-1

Cell Research (2014) 24:742-761. doi:10.1038/cr.2014.53; published online 29 April 2014

\section{Introduction}

Macrophages are crucial components of the immune system, and play pivotal roles in the primary response to pathogens as well as in coordination of the adaptive immune response, inflammation resolution, tissue homeostasis and repair [1]. Macrophage colony-stimulating

\footnotetext{
*These two authors contributed equally to this work.

Correspondence: Lingqiang Zhang ${ }^{\mathrm{a}}$, Fuchu $\mathrm{He}^{\mathrm{b}}$

${ }^{a} E-m a i l: z h a n g l q @$ nic.bmi.ac.cn

${ }^{b}$ E-mail: hefc@nic.bmi.ac.cn

Received 27 September 2013; revised 25 January 2014; accepted 27 February 2014; published online 29 April 2014
}

factor (M-CSF, also known as CSF-1) is crucial for the proliferation, survival and differentiation of macrophages as well as their precursors [2-4]. M-CSF-null (op/op) mice develop osteopetrosis due to lack of osteoclasts, as along with defects in tissue macrophages and blood monocytes [5]. M-CSF binds to CSF-1 receptor (CSF-1R, also known as M-CSFR or CD115), activating diverse downstream signaling events [4, 6-7]. Specifically, the phosphoinositide 3-kinase (PI3K)/Akt and Erk signaling pathways are essential for the proliferation of macrophages and their precursors [8-10].

The PI3K/Akt pathway serves a central role in the regulation of cell proliferation, survival and metabolism [11]. Binding of growth factors, including M-CSF, to 
receptor tyrosine kinases activates PI3K [12], triggering the production of phosphatidylinositol $(3,4,5)$-trisphosphate $\left(\mathrm{PIP}_{3}\right)$ on the inner side of the plasma membrane. Akt is recruited to the plasma membrane and activated through direct docking with its pleckstrin homology $(\mathrm{PH})$ domain to $\mathrm{PIP}_{3}$. Activated Akt phosphorylates its downstream targets to induce cell proliferation and differentiation. Glycogen synthase kinase $3 \beta$ (GSK3 3 ) is one of such substrates, which is usually constitutively active in unstimulated cells and inactivated by Akt-mediated phosphorylation on Serine 9 (Ser9) [13]. Upon M-CSF stimulation, Akt is rapidly activated by PI3K, leading to the phosphorylation of GSK3 $\beta[8,14]$; inactivation of GSK3 $\beta$ releases $\beta$-catenin, a co-activator for the LEF and TCF family of transcription factors, from degradation, thus promoting macrophage proliferation [15]. Compared with the activation mechanism of macrophage proliferation, less is known about how this process is terminated.

Casein kinase 2-interacting protein-1 (CKIP-1, also known as PLEKHO1) is a $\mathrm{PH}$ domain-containing protein involved in tumor cell proliferation, muscle cell differentiation, cell apoptosis and regulation of cell morphology [16-20]. We previously showed that CKIP-1-deficient mice displayed a higher bone mass due to increased osteoblast differentiation [21]. CKIP-1 also inhibits cardiac hypertrophy by promoting dephosphorylation of HDAC4 through recruiting the phosphatase PP2A, promoting the nuclear translocation of HDAC4 and inhibiting the transcriptional activity of MEF2C [22]. CKIP-1 is widely expressed in a variety of tissues and cells including macrophages [23]. A recent study showed that CKIP-1 expression was elevated upon LPS challenge in the human monocyte cell line THP-1 [24]. Here, we report that CKIP-1 is a novel regulator of macrophage proliferation and M-CSF signaling by interacting with TRAF6 and inhibiting Akt activation. CKIP-1-deficiency results in prolonged activation of Akt, and $C K I P-1^{-/-}$mice spontaneously develop a macrophage-dominated splenomegaly and myeloproliferation.

\section{Results}

CKIP-1 is upregulated during macrophage differentiation

We analyzed CKIP-1 expression profile using mouse organs and found that it was highly expressed in lymph nodes and spleen, and it was weakly expressed in bone marrow cells (BMCs) (Figure 1A). Further analysis showed that CKIP-1 was abundantly expressed in splenic macrophages and $\mathrm{CD} 11 \mathrm{~b}^{+}$myeloid cells, compared with B and T lymphocytes (Figure 1B). During the differentiation of human monocytes or murine BMCs into macrophages in M-CSF-conditioned medium, CKIP-1 expression was significantly elevated (Figure 1C). The CKIP-1 upregulation was observed throughout the whole induction process of bone marrow-derived macrophages (BMDMs) in vitro (Figure 1D). These data suggest that CKIP-1 might be involved in the development of macrophages.

To address the potential role of CKIP-1 in macrophage development, we cultured BMCs from CKIP-1-deficient and wild-type (WT) mice with M-CSF and observed an excessive yield of $C K I P-1^{-1-}$ macrophages compared with that of WT (Figure 1E). CD11b and F4/80 double positive cells were examined at day 3, 5 and 7 to determine the efficiency of the induction, and no significant differences were observed between cultures of CKIP$1^{-/}$BMCs and that of their WT counterparts (Figure 1F). This result led us to further investigate the role of CKIP1 in macrophage development in response to M-CSF.

Accelerated proliferation and improved survival of $C K$ IP-1-deficient BMDMs

The increased number of macrophages might be due to more efficient proliferation and/or less cell death. We analyzed cell cycle status of day 3,5 and 7 of cultures. The percentages of CKIP-1-deficient BMDMs in S and G2/M phases were higher relative to WT BMDMs at each time point (Figure 2A). We also quantified the proliferation of WT and CKIP-1-deficient BMDMs by analyzing BrdU incorporation. $41.4 \%$ of CKIP-1-deficient cells incorporated BrdU, compared with $21.3 \%$ of WT cells (Figure 2B), confirming the hyperproliferative response to M-CSF of CKIP-1-deficient cells. To verify the role of CKIP-1 in cell cycle progression, we measured the expression levels of mRNA transcripts encoding cell cycle-regulatory proteins in BMDMs. CKIP-1-deficient cells expressed more c-Myc and cyclin D2 mRNA at day 3 and 5 and more cyclin D1 mRNA at day 5 of cultures, compared with WT cells (Figure 2C).

We next assessed whether CKIP-1 deficiency influenced cell death. CKIP-1-deficient and WT BMDMs were cultured in the presence of M-CSF for 5 days, and then switched to M-CSF-free medium for 2 more days. CKIP-1-deficient cells displayed a decreased percentage of apoptosis after M-CSF deprivation (Figure 2D).

32D cells are bone marrow-derived, IL-3-dependent myeloid progenitors. Due to a lack of endogenous CSF$1 \mathrm{R}$, these cells respond poorly to M-CSF. After being reconstituted with CSF-1R, they can survive and proliferate upon M-CSF treatment [8]. To further investigate the inhibiting effect of CKIP-1 on cell proliferation, we constructed a CSF-1R stably expressed 32D cell line (32D-CSF1R). In 32D-CSF1R cells, overexpression of 

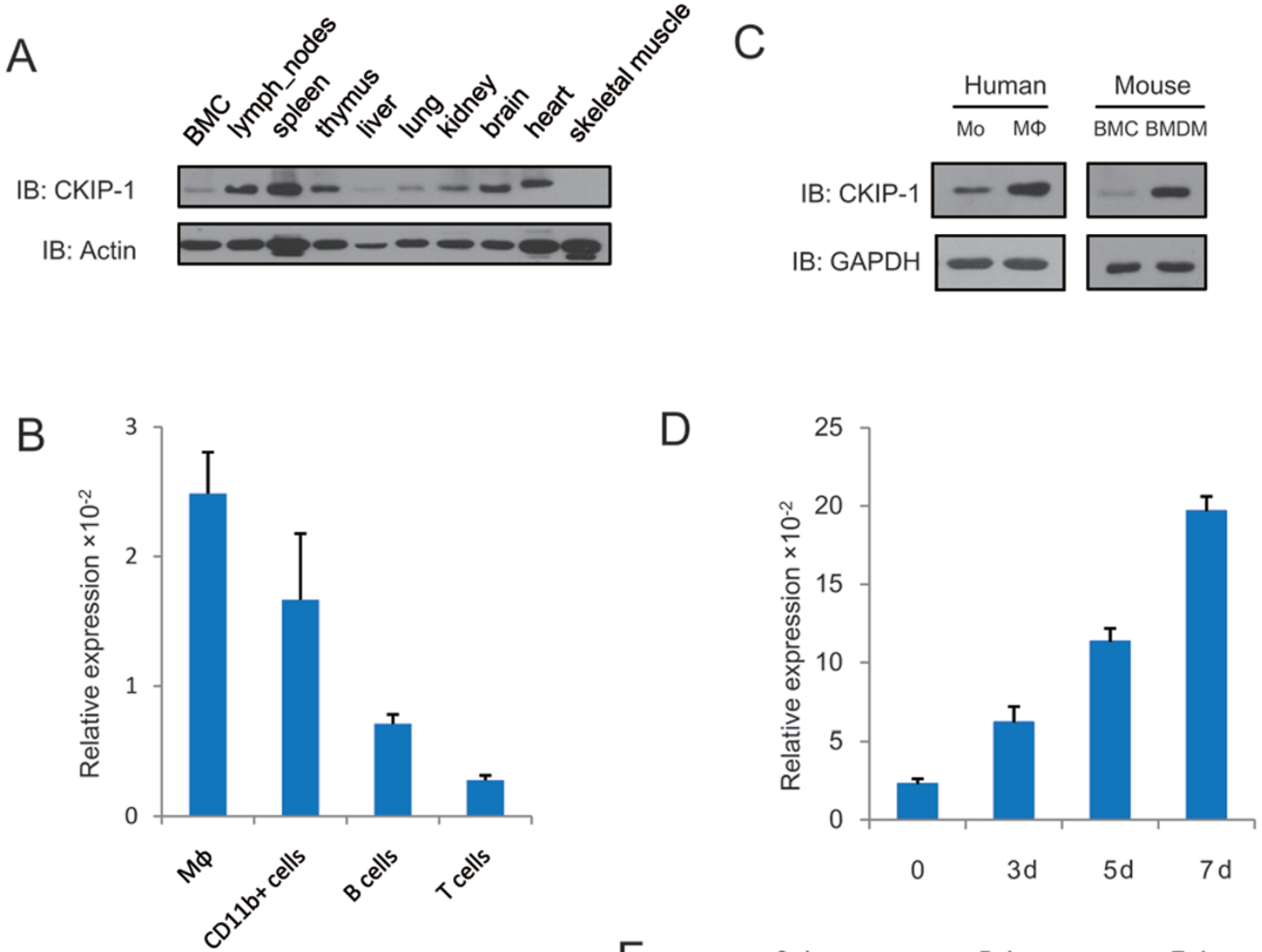

$E$

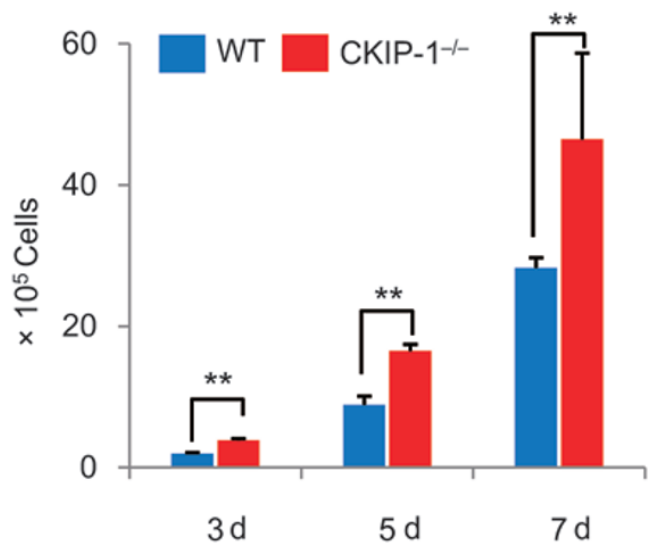

F
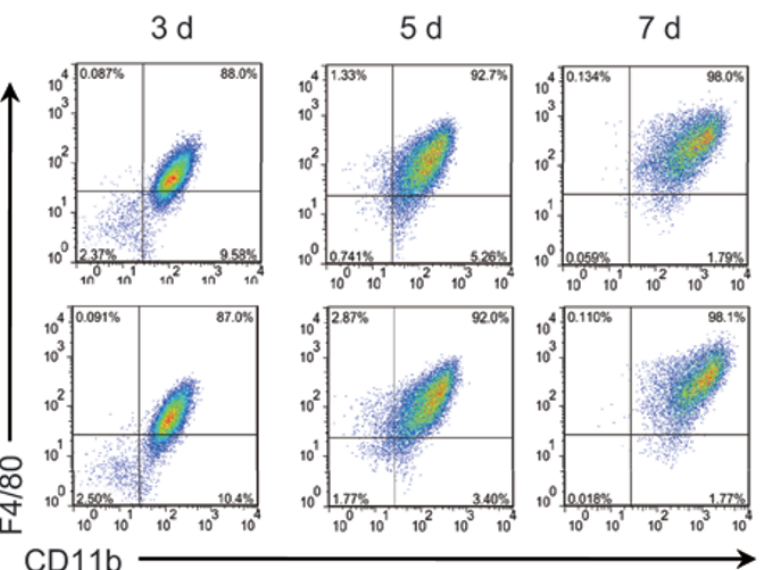

Figure 1 CKIP-1 is upregulated during macrophage differentiation. (A) Western blot analysis of CKIP-1 protein expression in mouse organs and BMCs. (B) Quantitative PCR analysis of CKIP-1 mRNA levels in mouse immune cells. Splenic macrophage $\left(\mathrm{CD} 11 \mathrm{~b}^{+} \mathrm{F} 4 / 80^{+}\right)$, myeloid cells $\left(\mathrm{CD} 11 \mathrm{~b}^{+}\right), \mathrm{B}$ cell $\left(\mathrm{CD} 19^{+}\right)$and $\mathrm{T}$ cell $\left(\mathrm{CD} 3^{+}\right)$were sorted, and total RNAs were extracted and then subjected to GPCR analysis. (C) CKIP-1 protein analysis in human monocyte (Mo), human monocyte-derived macrophages (monocytes were differentiated in 1640 medium containing $50 \mathrm{ng} / \mathrm{ml}$ hM-CSF for 5 days), murine BMCs and BMDMs. (D) Murine BMCs were induced to differentiate into macrophages for the indicated times in 1640 medium containing 20 $\mathrm{ng} / \mathrm{ml} \mathrm{mM}-\mathrm{CSF}$. Quantitative PCR was performed. (E) The numbers of BMDMs that were induced at various times ( $x$ axis) in cultures of WT and CKIP-1 $1^{-/-}$BMCs with fresh medium changed every other day. (F) WT (upper) and CKIP-1 $1^{-1-}$ (lower) BMCs were induced to differentiate into macrophages as the same as in E, CD11b and F4/80 double positive cells were determined by flow cytometry at each time point as indicated. Data shown are representative of three independent experiments (mean \pm $\mathrm{SD}),{ }^{* *} P<0.01$. 
A $3 d$
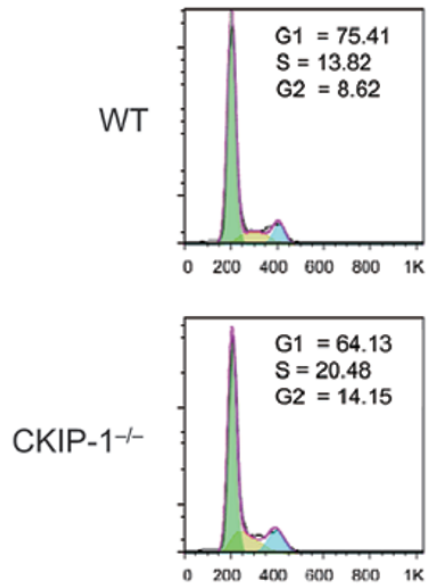

PI
$5 d$
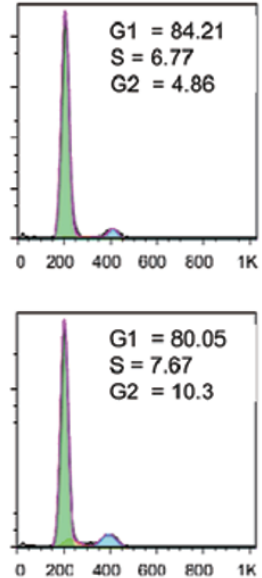

$0.200-400-600-800-1 \mathrm{~K}$
$7 d$
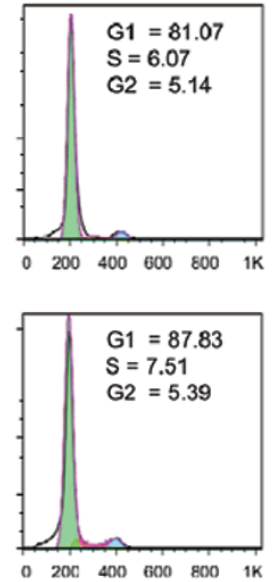

$\begin{array}{llllll}0 & 200 & 400 & 600 & 800 & 16\end{array}$

B
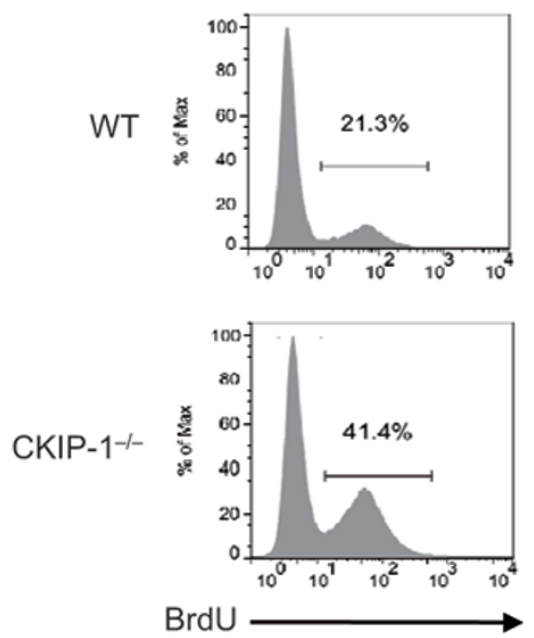

BrdU
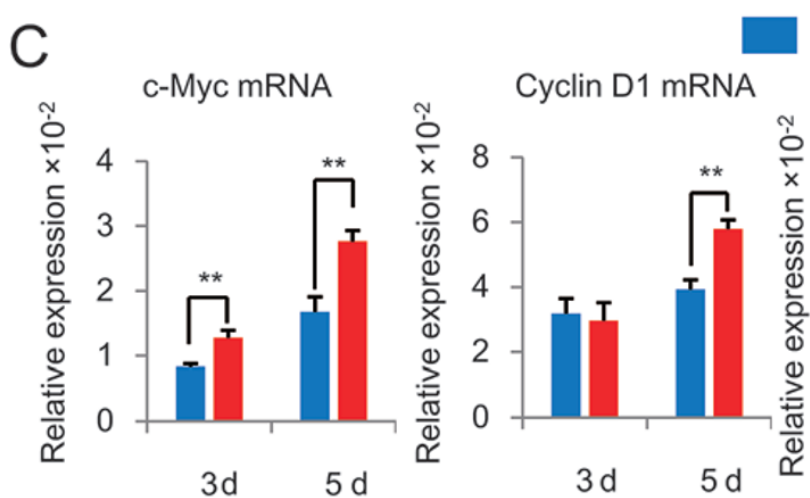

\section{WT}

CKIP-1-1Cyclin D2 mRNA

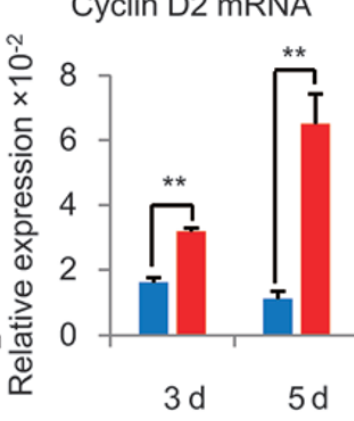

D
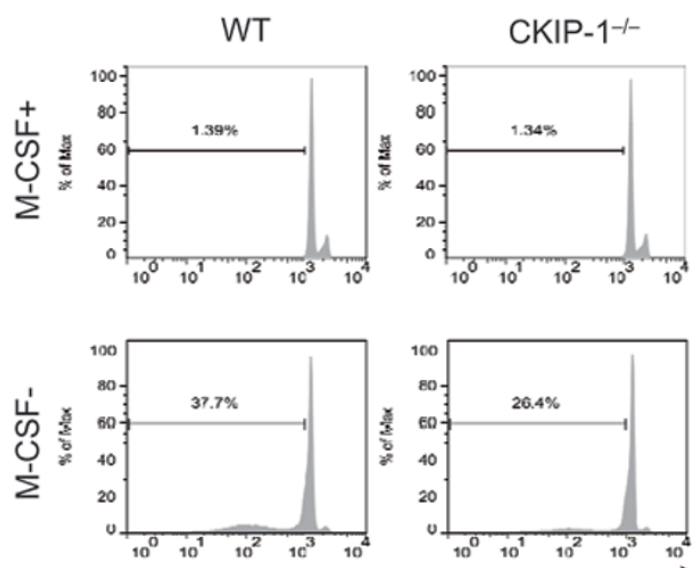

$\mathrm{Pl}$
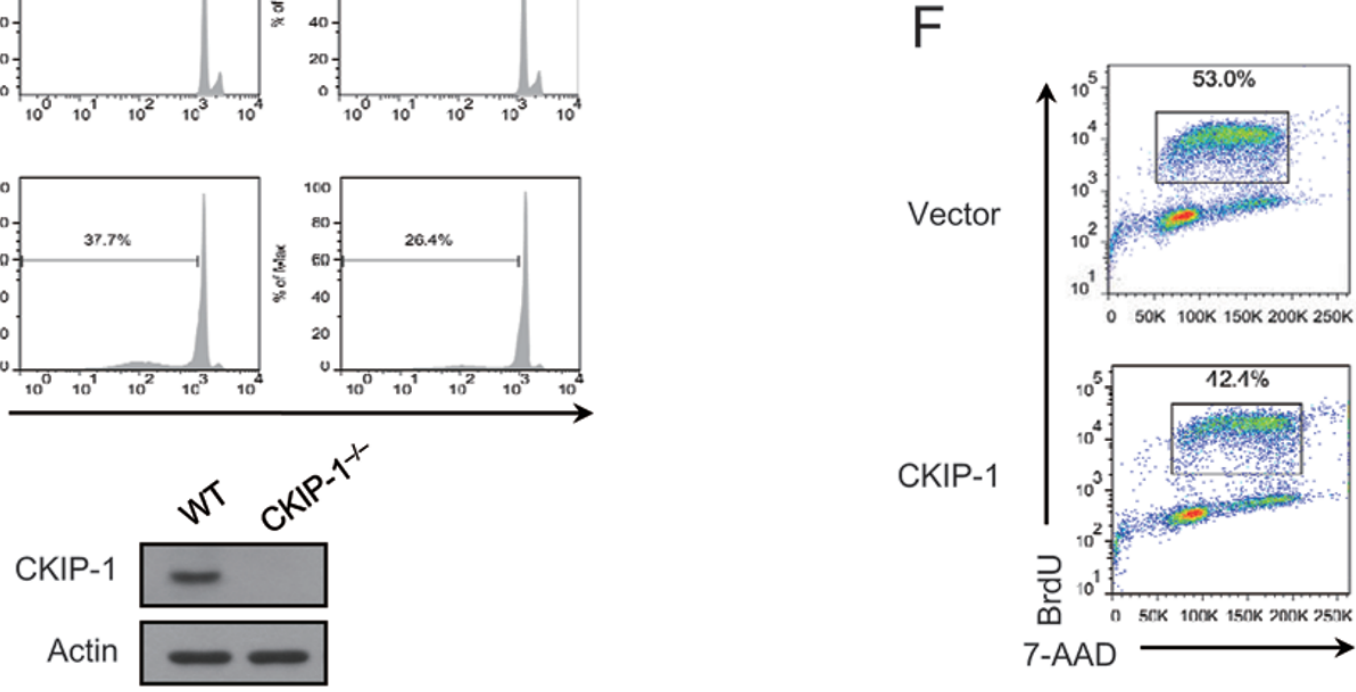
CKIP-1 decreased cell proliferation in the presence of $\mathrm{M}-\mathrm{CSF}$, compared with empty vector control (Figure 2E). BrdU incorporation assay confirmed this conclusion (Figure 2F). These data suggest that CKIP-1 negatively regulates macrophage proliferation and contributes to $\mathrm{M}$ CSF deprivation-induced apoptosis.

Previous studies showed that macrophage proliferation and differentiation might be coordinately regulated $[15$, 25]. We then sought to test whether CKIP-1 deficiency affected the differentiation of BMCs into mature macrophages in vitro. Both CKIP-1-deficient and WT BMDMs expressed classical macrophage markers including CD36, ApoE, CD115, MHC II, CD11b, F4/80 and CD284, as analyzed by flow cytometry or qPCR. Among the seven markers examined, five (CD11b, F4/80, CD115, CD284 and MHC II) showed no significant differences between CKIP-1-deficient and WT cells. CD36 and ApoE were even expressed at higher levels in CKIP-1-deficient BMDMs than in WT cells (Supplementary information, Figure S1A, S1B). The proliferative response of myelomonocytic progenitors to M-CSF is lost upon terminal differentiation to macrophages [25]. Whether CKIP-1 disruption can push mature macrophages into cell cycle was unknown. We tested this by using thioglycollateelicited peritoneal macrophages (TEMs) from $C K I P-1^{-1}$ and WT mice. CKIP-1 deficiency did not push TEMs into proliferation either in the presence or absence of MCSF (Supplementary information, Figure S1C). Collectively, our data indicate that accelerated proliferation of CKIP-1-deficient macrophages upon M-CSF stimulation is not due to impaired macrophage differentiation.

CKIP-1-deficient BMDMs exhibit prolonged Akt activation upon M-CSF stimulation

The excessive proliferation and improved survival of M-CSF-induced CKIP- $1^{-1-}$ macrophages indicate that CKIP-1 is involved in the regulation of M-CSF signal- ing. Studies have demonstrated that binding of M-CSF to CSF-1R activates PI3K and Erk signaling to promote macrophage proliferation and survival. Thus, we sought to stimulate WT and CKIP-1 $1^{-1-}$ BMDMs with M-CSF for various times and analyzed these signaling pathways. Sustained phosphorylation of Akt, the major target of PI3K, was detected in $C K I P-1^{-1-}$ macrophages (Figure $3 \mathrm{~A})$. By contrast, Erk and p38 activation was not affected by CKIP-1 deficiency (Figure 3A). Furthermore, we observed prolonged and enhanced GSK3 $\beta$ phosphorylation under M-CSF stimulation in CKIP-1-deficient BMDMs (Figure 3B). Similarly, in a murine macrophage cell line, RAW264.7 cells, depletion of CKIP-1 by shRNA resulted in sustained activation of Akt-GSK3 $\beta$ signaling upon M-CSF treatment (Supplementary information, Figure S2). It has been shown that Akt phosphorylates GSK3 $\beta$ in a variety of cellular processes and multiple cell types [11], so we tested whether M-CSF-induced-GSK3 $\beta$ phosphorylation in macrophages depends on Akt or not. Our results showed that pre-treating BMDMs with the PI3K inhibitor LY294002 efficiently reduced GSK $3 \beta$ phosphorylation after M-CSF stimulation, suggesting that MCSF-induced GSK3 $\beta$ phosphorylation depends, at least partially, on Akt (Figure 3C).

To assess the contribution of excessive activation of Akt to the accelerated proliferation of CKIP-1-deficient BMDMs, we treated CKIP-1-deficient and WT BMDMs with the PI3K inhibitor LY294002. Similar to WT cells, $\mathrm{BrdU}^{+}$cells in CKIP- ${ }^{-/-}$BMDMs were dramatically decreased after LY294002 treatment (Figure 3D), suggesting that CKIP-1 regulates macrophage proliferation mainly by inhibiting the PI3K-Akt pathway.

As CKIP-1 and Akt both contain a PH domain essential for plasma membrane recruitment, we wondered whether CKIP-1 inhibits Akt through impairing Akt membrane recruitment. Overexpression of CKIP-1 reduced the membrane-anchoring period of Akt upon M-

Figure 2 Enhanced proliferation and survival of CKIP-1-deficient BMDMs. (A) Murine BMCs were cultured in mM-CSF-containing medium to induce the differentiation into macrophages for the indicated times. Flow cytometry using propidium iodide (PI) was performed to analyze cell cycle. (B) Proliferation of BMDMs was examined by flow cytometry. Numbers above bracketed lines indicate percent of BrdU cells. (C) Quantitative PCR analysis of the expression levels of cell cycle-related genes c-Myc, cyclin D1 and cyclin D2 in WT and CKIP-1 $1^{-1-}$ BMDMs cultured in the presence of mM-CSF (20 ng/ml) for the indicated times. Data are presented relative to the expression of GAPDH (mean \pm SD). ${ }^{* *} P<0.01$. (D) WT and CKIP-1 $1^{-1-}$ BMDMs were cultured in the presence of M-CSF for 5 days, followed by culturing in M-CSF-free medium for another 2 days. Then apoptosis rates were analyzed by PI exclusion assay (upper panel). Numbers above bracketed lines indicate percentage of hypodiploid cells. CKIP-1 expression level was determined by immunoblotting (IB) (lower panel). (E) 32D-CSF1R cells transfected with CKIP-1 and control vectors by a lentiviral system were plated in six-well plates at a density of $5 \times 10^{4}$ cells $/ \mathrm{ml}$, and cultured in 1640 medium containing $50 \mathrm{ng} / \mathrm{ml} \mathrm{mM}-\mathrm{CSF}$. Cell numbers were determined by a cell counter at the indicated time (upper panel). CKIP-1 expression levels were determined by IB (lower panel). (F) 32D-CSF1R cells in E were starved of cytokines for $8 \mathrm{~h}$, and incubated in 1640 medium containing mM-CSF (20 ng/ml). BrdU (10 $\mu \mathrm{M})$ was added into the medium 1 $\mathrm{h}$ before the harvest. Cells were then harvested and the percentage of $\mathrm{BrdU}^{+}$cells were analyzed by flow cytometry. Data are representative of three independent experiments. 
A

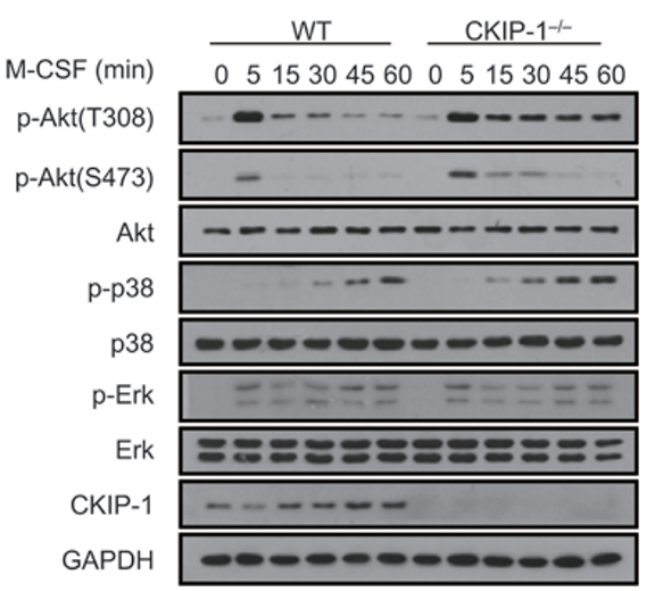

B
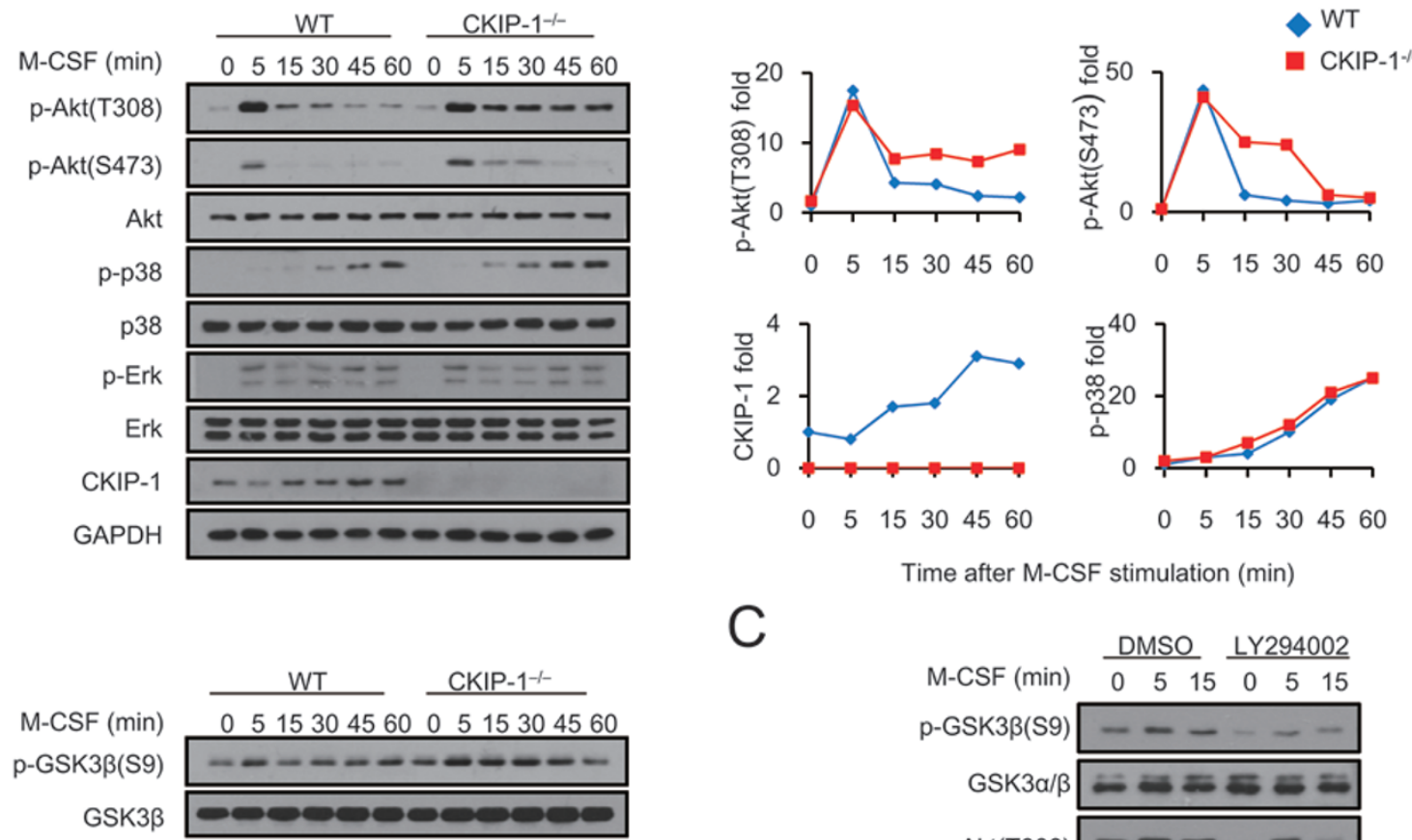

$\begin{array}{llllll}0 & 5 & 15 & 30 & 45 & 60\end{array}$

$\begin{array}{llllll}0 & 5 & 15 & 30 & 45 & 60\end{array}$

Time after M-CSF stimulation (min)

C

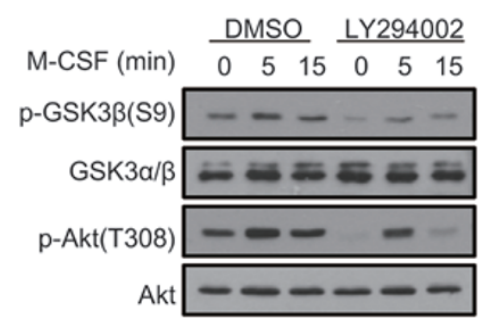

D
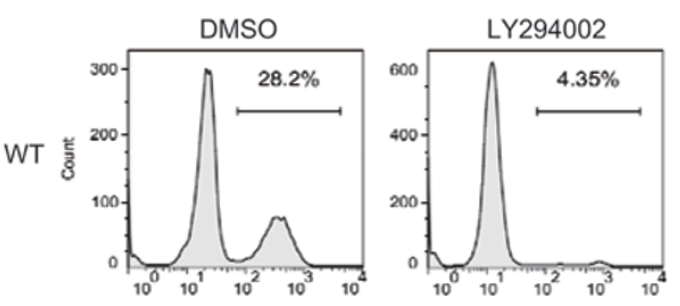

E
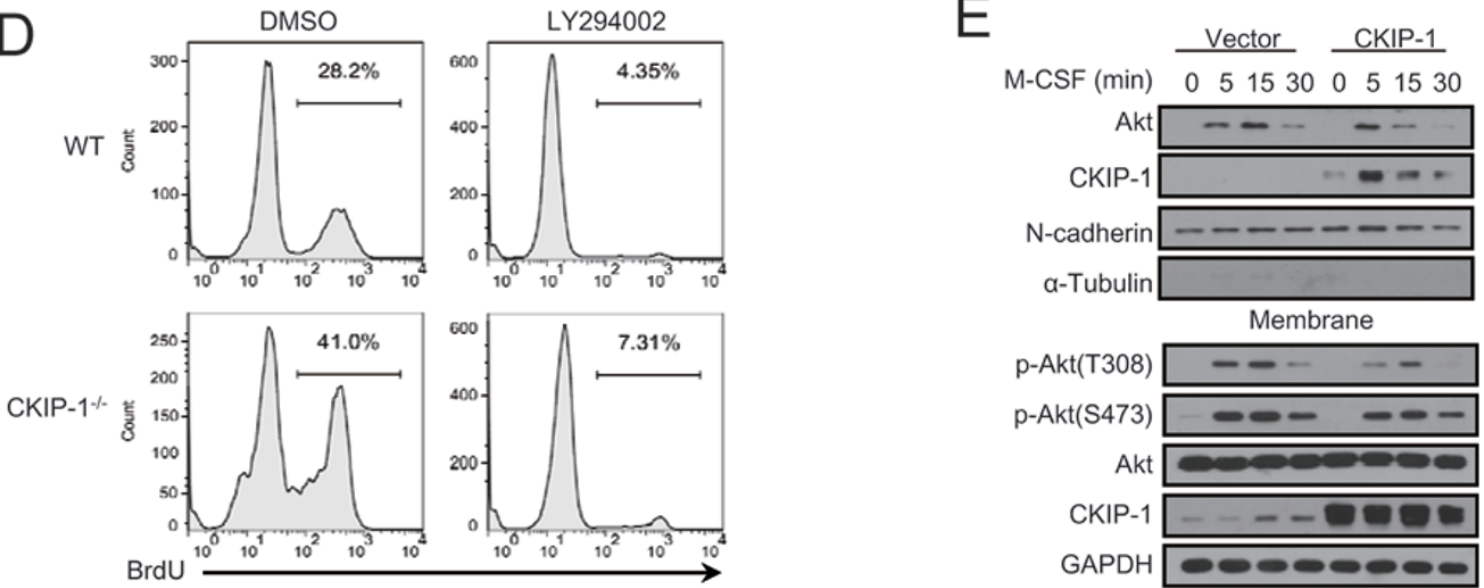

F

G

WCE
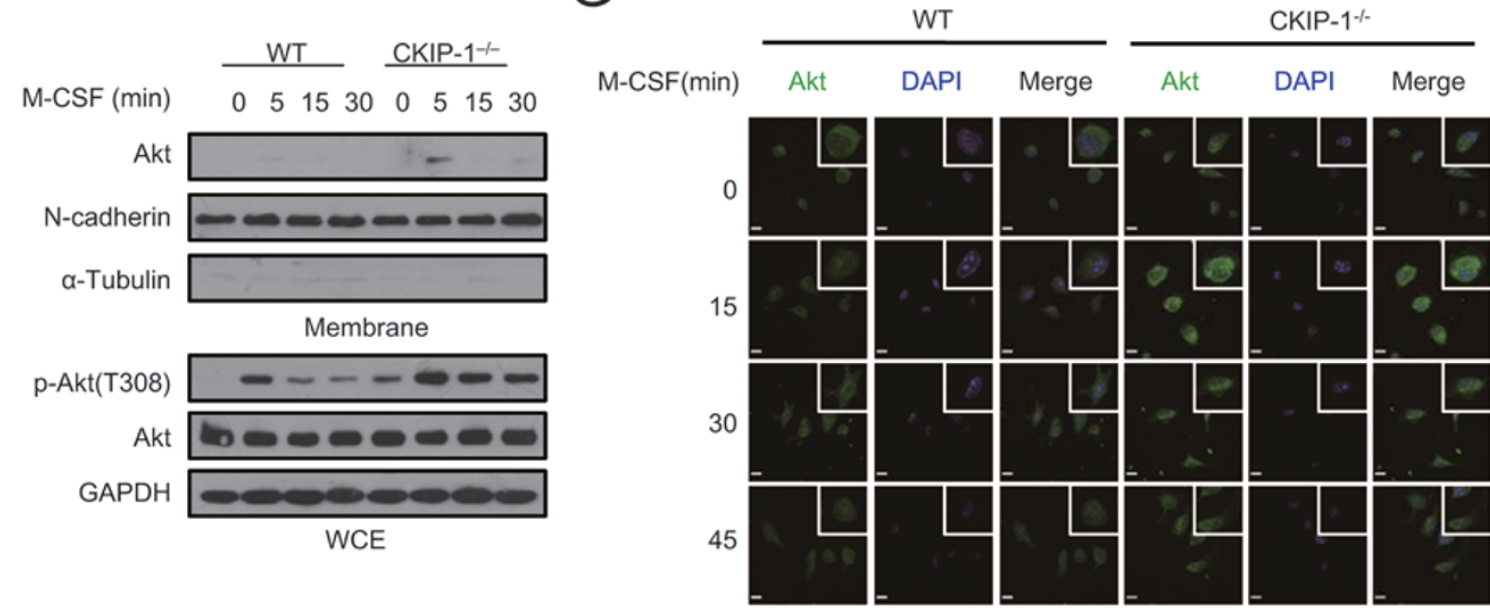
CSF stimulation and inhibited the cytosol Akt phosphorylation, especially on Thr308 in RAW264.7 cells (Figure $3 \mathrm{E})$. Conversely, more Akt proteins were detected in the membrane fraction of $C K I P-1^{-1-}$ BMDMs than that of WT cells at 5 min after M-CSF stimulation (Figure 3F). Consistently, immunofluorescence (IF) analysis showed that more Akt proteins were localized on the membranes of $C K I P-1^{-/}$BMDMs than that of WT cells at each time points after M-CSF stimulation (Figure 3G). These results indicate that CKIP-1 inhibits M-CSF-induced Akt activation through impairing Akt membrane recruitment.

\section{TRAF6 is involved in M-CSF signaling}

The ubiquitin ligase TRAF6 (tumour necrosis factor receptor associated factor 6) promotes the K63-linked ubiquitination of Akt, and is required for plasma membrane translocation of Akt [26]. Previous studies have shown that TRAF6 is indispensable for osteoclast differentiation and maturation [27-28], but its role in the development of their myeloid precusors, monocytes and macrophages, is not well elaborated. We thus tested the role of TRAF6 in M-CSF-induced myeloid cell proliferation. Knockdown of TRAF6 by shRNA dramatically decreased the proliferation of 32D-CSF1R cells when they were cultured with M-CSF-conditioned medium (Figure 4A). Data of BrdU incorporation assay also supported this notion (Figure 4B). We further analyzed whether TRAF6 is involved in M-CSF-induced Akt activation. Knockdown of TRAF6 attenuated Akt phosphorylation upon M-CSF stimulation both in 32D-CSF1R and RAW264.7 cells (Figure 4C and Supplementary information, Figure S3A). To verify the role of TRAF6 in M-CSF signaling, we treated RAW264.7 cells with MCSF and checked TRAF6 ubiquitination, which reflects autoactivation of the TRAF6 ligase. Like other growth factors such as IGF-1 [26], M-CSF treatment induced the ubiquitination of TRAF6 (Supplementary information, Figure S3B). We also observed the ubiquitination of Akt upon M-CSF stimulation (Supplementary information,
Figure S3C). The interaction between TRAF6 and MCSF receptor was detectable as well (Supplementary information, Figure S3D). These results suggest that TRAF6 participates in M-CSF signaling and promotes Akt activation downstream of M-CSF.

\section{CKIP-1 interacts with TRAF6 and inhibits TRAF6-medi- ated ubiquitination of Akt}

A previous study showed that CKIP-1 inhibits Akt activation in cancer cells [29]. However, the physiological role of such regulation in normal cells and the underlying mechanism were not well elaborated. As CKIP-1 impaired Akt membrane recruitment, we hypothesized that CKIP-1 may interact with TRAF6 to antagonize its promoting effect on Akt. CKIP-1 interacted with TRAF6 both in vitro and in cultured mammalian cells (Figure 4D-4E). The interaction between endogenous CKIP-1 and TRAF6 was specifically observed upon M-CSF stimulation (Figure 4F). We also constructed two truncated forms of TRAF 6 to map the CKIP-1 binding region. The TRAF domain of TRAF6 interacted with CKIP-1, while the TRAF6 $\triangle$ TRAF, which contains the RING and zinc fingers did not (Supplementary information, Figure S3E). Since binding to the TRAF domain of TRAF6 may inhibit ubiquitination [30], we determined whether CKIP1 affects TRAF6 autoubiquitination and its E3 ligase activity toward Akt. Overexpression of CKIP-1 dramatically inhibited TRAF6 autoubiquitination and TRAF6mediated Akt ubiquitination (K63-linkage) (Figure 4G$4 \mathrm{H})$. These results indicate that CKIP-1 interacted with TRAF6 and inhibits TRAF6-mediated Akt activation.

$N F-\kappa B$ signaling plays a central role in the immune system by regulating several processes ranging from the development and survival of lymphocytes to the control of immune responses [31]. Growing studies revealed that $\mathrm{NF}-\kappa \mathrm{B}$ activation is required for monocyte and macrophage survival [32]. However, it is still controversial whether M-CSF can activate NF- $\kappa B$ [33-34]. We found that IKK $\alpha / \beta$ phosphorylation and I $\mathrm{KB}$ degradation were

Figure 3 CKIP-1 inhibits M-CSF-induced PI3K-Akt-GSK3 $\beta$ signaling. (A) WT and CKIP-1 $1^{-/-}$BMDMs were starved of M-CSF for $4 \mathrm{~h}$, restimulated with M-CSF $(50 \mathrm{ng} / \mathrm{ml})$ for various periods, and harvested for IB analysis with the indicated antibodies (left). Right panels represent results of the densitometric analyses. (B) WT and CKIP- $1^{-1-}$ BMDMs were treated as in A and then harvested for IB analysis with GSK3 $\beta$ and phosphor-GSK3 $\beta$ antibodies (C) BMDMs were stimulated with mM-CSF in the presence of absence of the PI3K inhibitor LY294002 (10 $\mu \mathrm{M})$. Total and phosphorylated protein levels of Akt and GSK3 $\beta$ were determined by western blot. (D) BrdU incorporation by BMDMs cultured in medium containing $20 \mathrm{ng} / \mathrm{ml} \mathrm{M}-\mathrm{CSF}$ in the presence of LY294002 $(10 \mu \mathrm{M})$ for $24 \mathrm{~h}$ was assessed by flow cytometry. (E) RAW264.7 cells were infected with mock or CKIP-1 retrovirus, serum-starved for 1 day and then restimulated with M-CSF (50 ng/ml) for various periods. The membrane fractions and whole cell extracts were then collected for IB analysis. (F) WT and CKIP-1 $1^{-1-}$ BMDMs were starved of M-CSF for $4 \mathrm{~h}$ and then restimulated with $\mathrm{M}-\mathrm{CSF}(50 \mathrm{ng} / \mathrm{ml})$ for various periods. The membrane fractions and whole cell extracts were collected for IB analysis with the indicated antibodies. (G) WT and CKIP-1 $1^{-/-}$BMDMs treated as in $\mathbf{F}$ were fixed for immunofluorescence analysis. Scale bar, $10 \mu \mathrm{m}$. Data are representative of three independent experiments. 
A

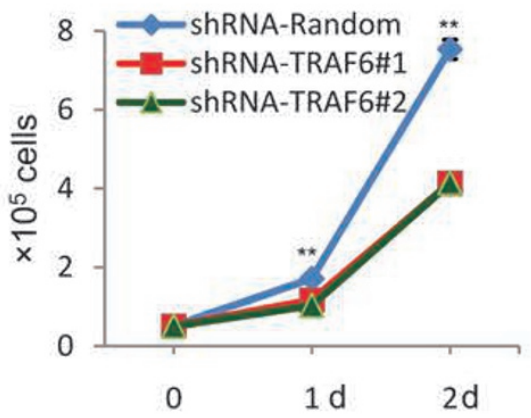

shRNA Random TRAF6\#1 TRAF6\#2

M-CSF (min) $0102030 \quad 0 \quad 102030 \quad 0 \quad 102030$

p-Akt(308)

p-Akt(S473)

Akt

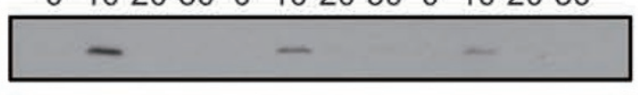

RAF6

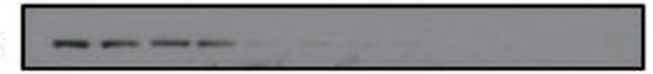

GAPDH

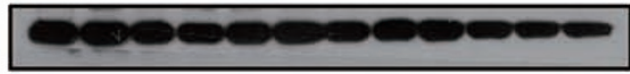

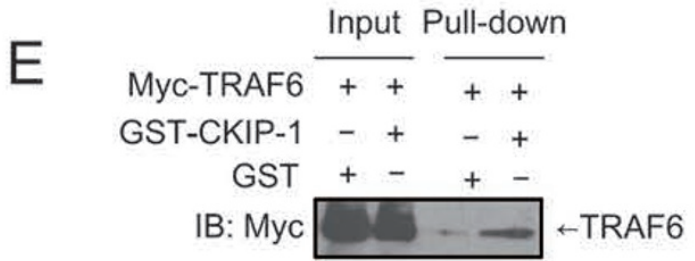

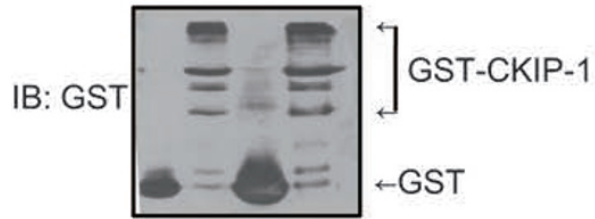

$G$

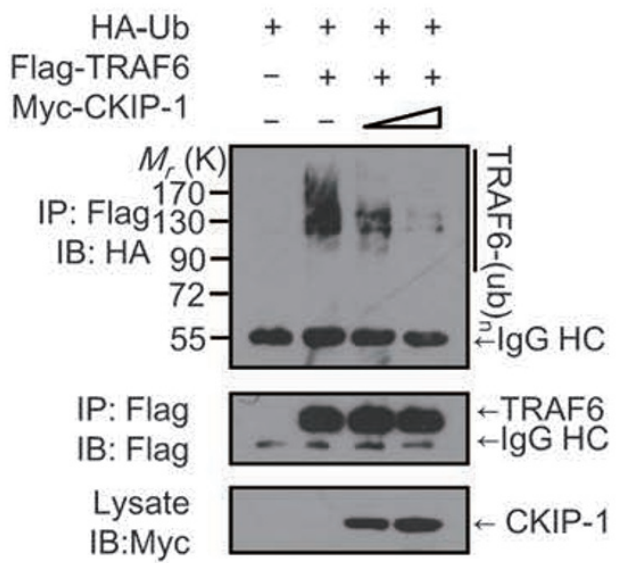

shRNA-Random

ShRNA-TRAF6\#1

ShRNA-TRAF6\#2
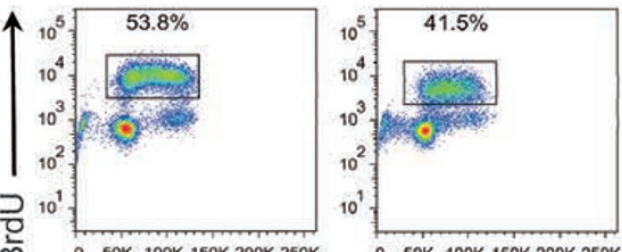

o $50 \mathrm{~K} 100 \mathrm{~K} 150 \mathrm{~K} 200 \mathrm{~K} 250 \mathrm{~K}$

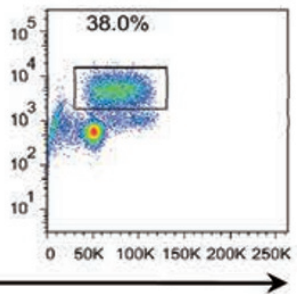

D

F

IP: IgG TRAF6

M-CSF (min) $\quad 0 \quad 0 \quad 1530 \quad 45$

IB: CKIP-1

IB: TRAF6 룰료 $\leftarrow$ TRAF6

IB: CKIP-1 -

IB: TRAF6 $-\cdots$

$\mathrm{H}$

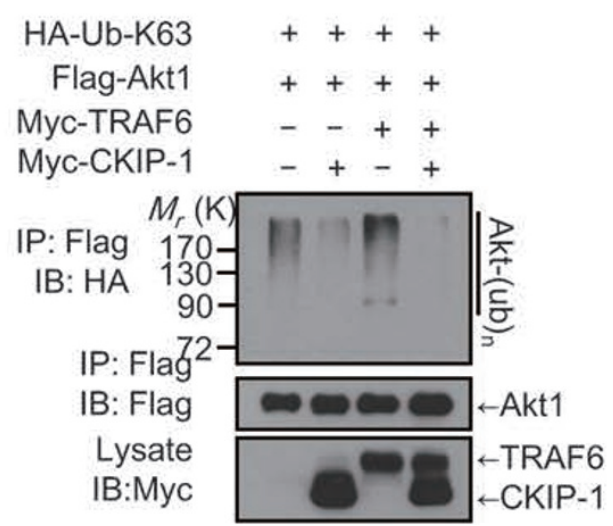


undetectable upon M-CSF stimulation even at a high concentration of $100 \mathrm{ng} / \mathrm{ml}$ (Figure 5A). As a positive control, LPS, a classical stimulus of NF- $\mathrm{BB}$ activation, induced IKK $\alpha / \beta$ phosphorylation and I $\mathrm{B}$ degradation in RAW264.7 cells as well as BMDMs. Both M-CSF and LPS induced JNK phosphorylation, and M-CSF remarkably induced Akt phosphorylation (Figure 5A). These results suggest that $\mathrm{M}-\mathrm{CSF}$ is not a potent inducer of $\mathrm{NF}-\mathrm{\kappa B}$ activation. Moreover, both in WT and CKIP-1 ${ }^{-/}$ BMDMs, M-CSF was unable to induce NF- $\mathrm{BB}$ activation (Figure 5B). One recent report showed that M-CSF can activate NF- $\kappa B$ by inducing p65 Ser276 phosphorylation and thus promoting its nuclear translocation [33], however this is not seen in our experiments performed on BMDMs. Consistent with other studies that showed $\mathrm{NF}-\kappa \mathrm{B}$ was constitutively activated in macrophages [32, 35], we observed constitutive phosphorylation of p65 at Ser276 (Figure 5B) and its nuclear localization in BMDMs (Figure 5C). CKIP-1 deficiency neither affected p65 Ser276 phosphorylation, nor the localization of Ser276phosphorylated p65 in BMDMs (Figure 5B-5C). Finally, we depleted endogenous $\mathrm{p} 65$ by shRNA in 32D-CSF1R cells, and found that there was no difference in M-CSFinduced proliferation between control and p65-depleted $32 \mathrm{D}$ cells (Figure $5 \mathrm{D}-5 \mathrm{E}$ ), consistent with a previous report [36]. Taken together, our results indicate that NF- $\kappa B$ signaling is not a major target pathway downstream of $\mathrm{M}-\mathrm{CSF}$ and that CKIP-1 does not affect NF- $\kappa \mathrm{B}$ signaling in $\mathrm{M}-\mathrm{CSF}$-induced macrophage proliferation.

\section{GSK3 $\beta$-mediated CKIP-1 phosphorylation promotes CKIP-1 degradation}

Intriguingly, we observed that the protein level of CKIP-1 itself was gradually increased within one hour after M-CSF treatment in BMDMs (Figures 3A and 6A) and also fluctuated in mouse macrophage RAW264.7 cells, i.e., first increased and then declined (Supplementary information, Figure S4A). During this period, CKIP1 mRNA alteration was not significant (Supplementary information, Figure S4B). Treatment with the protein synthesis inhibitor cycloheximide (CHX) showed that CKIP-1 was a short-life protein in BMDMs (Figure 6B) and RAW264.7 cells (Supplementary information, Figure S4C). Treatment with the proteasome inhibitor MG132 resulted in an accumulation of CKIP-1 protein (Figure 6C; Supplementary information, Figure S4D), suggesting that CKIP-1 was degraded by the proteasome. We also observed that treatment with the PI3K inhibitor LY294002 or Wortmannin promoted CKIP-1 degradation, whereas treatment with the GSK3 $\beta$ inhibitor SB216763 or LiCl prevented its degradation in BMDMs and RAW264.7 cells (Figure 6D and Supplementary information, Figure S4E, S4F). In comparison, treatment with the Erk inhibitor UO126 or the p38 inhibitor SB203580 had no significant effects on CKIP-1 protein levels (Figure 6D; Supplementary information, Figure S4E). It has been well-defined that PI3K activates Akt and then Akt inactivates GSK3 $\beta$ through phosphorylation [13]. These observations suggest that GSK3 $\beta$ might promote CKIP-1 degradation, whereas PI3K-Akt signaling promotes CKIP-1 stabilization.

As a multi-functional protein kinase, GSK3 3 catalyzes the phosphorylation of various substrates. Some substrates, upon phosphorylation, are further ubiquitinated and degraded by the proteasome. We then hypothesized that CKIP-1 might be also a substrate of GSK3 $\beta$. Depletion of endogenous GSK3 $\beta$ by shRNA in RAW264.7 cells resulted in stabilization of CKIP-1 (Figure 6E). GSK $3 \beta$ could be detected in the anti-CKIP-1 immunoprecipitates of macrophage lysates (Figure 6F). Mass spectrometry identified Ser341 of murine CKIP-1 (corresponding to Ser342 of human CKIP-1) was phosphory-

Figure 4 CKIP-1 interacts with TRAF6 and inhibits TRAF6-mediated Akt ubiquitination. (A) 32D-CSF1R cells transfected with TRAF6-shRNA \#1, \#2 or random shRNA by lentivirus were plated in six-well plates at a density of $5 \times 10^{4}$ cells/plate, and cultured in 1640 medium containing mM-CSF $(50 \mathrm{ng} / \mathrm{ml})$. Cell numbers were determined by a cell counter. (B) 32D-CSF1R cells prepared as in A were starved of cytokines for $8 \mathrm{~h}$, and incubated in 1640 medium containing mM-CSF (20 ng/ml), and BrdU $(10 \mu \mathrm{M})$ was added $1 \mathrm{~h}$ before harvest. Percentage of BrdU ${ }^{+}$cells was determined by flow cytometry. (C) 32D-CSF1R cells were starved of cytokines for $8 \mathrm{~h}$, and incubated with mM-CSF $(20 \mathrm{ng} / \mathrm{ml})$. Akt phosphorylation was examined by IB. (D) TRAF6 and CKIP-1 were transfected into 293T cells as indicated. TRAF6 proteins were immunoprecipitated by anti-Myc antibody. Both the whole-cell lysates (WCE) and the immunoprecipitates were analyzed by IB with anti-Myc or anti-Flag antibody. (E) GST pull-down assay of TRAF6 and GST-CKIP-1 in vitro. (F) BMDMs were stimulated with M-CSF for the indicated times. The cell lysates were immunoprecipitated with anti-TRAF6 antibody or control IgG. Both the WCE and the immunoprecipitates were analyzed to detect the expression of CKIP-1 and TRAF6. (G) In vivo ubiquitination assay in 293T cells transfected with Flag-TRAF6, HA-ubiquitin (Ub), along with Myc-CKIP-1. TRAF6 proteins were immunoprecipitated and then analyzed by IB with the anti-HA antibody to detect the ubiquitination. (H) In vivo ubiquitination assay in 293T cells transfected with FlagAkt1, HA-Ub-K63 (K63-only ubiquitin) and Myc-TRAF6, along with CKIP-1. Ubiquitinated Akt1 was detected in Akt1 immunoprecipitates. Data are representative of three independent experiments. 

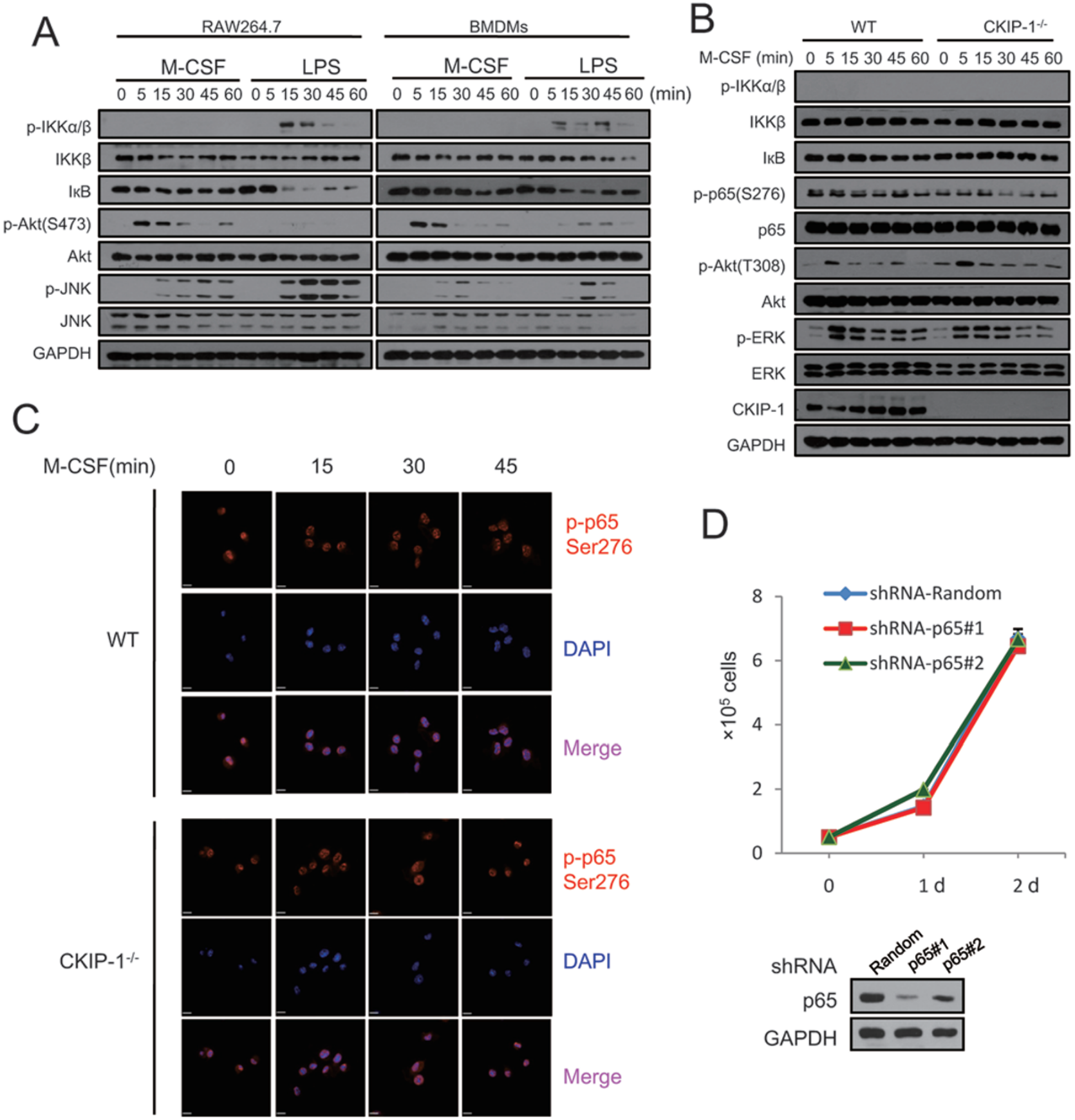

E

shRNA-Random

shRNA-p65\#1

shRNA-p65\#2
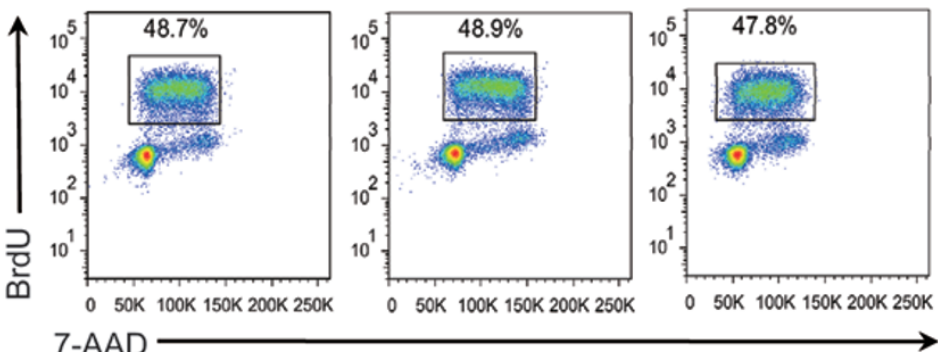

7-AAD 
lated in RAW264.7 cells (Figure 6G). This serine site conforms to the consensus phosphorylation motif by GSK $3 \beta$ and is conserved across species (Supplementary information, Figure S4G).

To further support the notion that human CKIP-1 is phosphorylated on Ser342 by GSK3 $\beta$, we raised an antibody and showed that it specifically recognizes Ser342phosphorylated human CKIP-1 in cultured cells since either $\lambda$-phosphatase treatment or adding phos-tag to the SDS-PAGE abolished the band of phosphorylated CKIP1 (Figure 6H). Mutation of CKIP-1 Ser342 to alanine (S342A) prevented its phosphorylation, whereas mutation to aspartate (S342D) mimicked the phosphorylation (Figure 6I). In vitro phosphorylation assay showed that CKIP-1 was phosphorylated by purified active GSK3 $\beta$ kinase (Figure 6J). To determine whether phosphorylation of CKIP-1 at Ser342 is regulated by GSK3 $\beta$ in vivo, exogenous CKIP-1 were overexpressed in 293T cells, and the cells were then treated with GSK3 $\beta$ inhibitor SB216763 or PI3K inhibitor LY294002, respectively. The level of CKIP-1 Ser342 phosphorylation decreased after treatment with SB216763 but was elevated by LY294002 (Figure 6K). Collectively, these data indicate that CKIP-1 is a bona fide substrate of GSK3 $\beta$.

We next determined whether GSK3 $\beta$ promotes CKIP1 ubiquitination. Ubiquitin-conjugated CKIP-1 adducts were readily detected in cultured cells (Figure 7A). Treatment with the GSK3 $\beta$ inhibitor $\mathrm{LiCl}$ or SB216763 reduced, whereas PI3K inhibitor LY294002 increased CKIP-1 ubiquitination (Figure 7A). The CKIP-1 S342A mutation abolished the ubiquitination (Figure 7B), suggesting that the Ser342 phosphorylation was required for CKIP-1 ubiquitination. To determine if phosphorylation of CKIP-1 at Ser342 leads to its instability, we generated S342A single and S342/346A double mutants and found that both mutants had a significantly prolonged half-life compared with that of WT CKIP-1 (Figure 7C).

Next, we investigated the dynamics of CKIP-1 phosphorylation and dephosphorylation in M-CSF-stimulated macrophages. Due to the difference of Ser342-flanking sequences between human and murine CKIP-1, our phosphorylation antibody does not well-recognize the phosphorylated murine CKIP-1 (data not shown). We then generated a RAW264.7 cell line stably expressing human CKIP-1 to investigate the effect of M-CSF on CKIP-1 phosphorylation and ubiquitination. M-CSF treatment resulted in a rapid reduction of Ser342-phosphorylation and ubiquitination levels of CKIP-1, accompanied by an increase of phosphorylation levels of Akt and GSK3 $\beta$ at the early stage (Figure 7D). After that, the phosphorylation and ubiquitination levels of CKIP-1 recovered, in line with the decline of phosphorylation levels of Akt and GSK3 $\beta$ (Figure 7D). These data suggest that M-CSF treatment led to GSK3 $\beta$ inactivation and consequently a reduction in the phosphorylation-driven ubiquitination of CKIP-1.

\section{Tissue macrophages are increased in CKIP-1-deficient} mice

Given the elevated proliferation and improved survival of CKIP-1-deficient BMDMs under M-CSF stimulation in vitro, we tried to determine whether there was any notable abnormality in vivo. We compared microglia in the brains and spinal cords of WT and CKIP-1-deficient mice by staining with the microglia marker Iba-1. More microglias were observed in the brain and spinal cord of $C K I P-1^{-/-}$mice, compared with those of WT mice (Figure 8A). Additionally, we noted that most $C K I P-1^{-/}$ mice spontaneously developed splenomegaly when they get older (Figure 8B). Histologically, splenic architecture was disorganized with enlarged lymphoid follicles (Figure $8 \mathrm{C})$. Flow cytometry revealed that the number of splenic macrophages and monocytes, but not $\mathrm{T}$ or $\mathrm{B}$ cells, were significantly increased in $C K I P-1^{-/-}$mice compared to WT littermates (Figure 8D). We also observed an increase in percentages of monocytic cells and CD11b myeloid progenitors in the $\mathrm{BM}$ of $C K I P-1^{-1-}$ mice (Figure $8 \mathrm{E}$ and $8 \mathrm{~F}$ ), but the percentages of myeloid cell populations in Mac-1/Gr-1 and Mac-1/F4/80 fractions were not changed (Figure $8 \mathrm{~F}$ ). Since M-CSF is known to play

Figure 5 CKIP-1 did not affect NF-kB activation in M-CSF-induced macrophage proliferation. (A) RAW264.7 cells or BMDMs were starved of M-CSF for $4 \mathrm{~h}$ and restimulated with M-CSF $(100 \mathrm{ng} / \mathrm{ml})$ or LPS $(100 \mathrm{ng} / \mathrm{ml})$ for various periods and harvested for IB analysis. (B) WT and CKIP-1 $1^{-1-}$ BMDMs were starved of M-CSF for $4 \mathrm{~h}$ and restimulated with $\mathrm{M}-\mathrm{CSF}(100 \mathrm{ng} / \mathrm{ml})$ for various periods and harvested for IB analysis. (C) WT and CKIP-1 ${ }^{-1-}$ BMDMs treated as in B were fixed for immunofluorescence with anti-p-p65 Ser276 antibody. The nuclei were stained with DAPI. Images were captured by confocal microscopy and merged as indicated. Scale bar, $10 \mu \mathrm{m}$. (D) 32D-CSF1R cells transfected with shRNA- p65 \#1, \#2 or shRNA- Random by a lentiviral system were plated in 6 -well plates at a density of $5 \times 10^{4}$ cells $/ \mathrm{ml}$, and cultured in 1640 medium containing 50 $\mathrm{ng} / \mathrm{ml} \mathrm{mM}-\mathrm{CSF}$. Cell numbers were determined by a cell counter at the indicated time (upper panel) and p65 expression was determined by IB (lower panel). (E) 32D-CSF1R cells in D were starved of cytokines for $8 \mathrm{~h}$, and incubated in 1640 medium containing mM-CSF $(20 \mathrm{ng} / \mathrm{ml})$ and BrdU $(10 \mu \mathrm{M})$ for $1 \mathrm{~h}$. Cells were then harvested and BrdU incorporation was determined by flow cytometry. Data are representative of three independent experiments. 


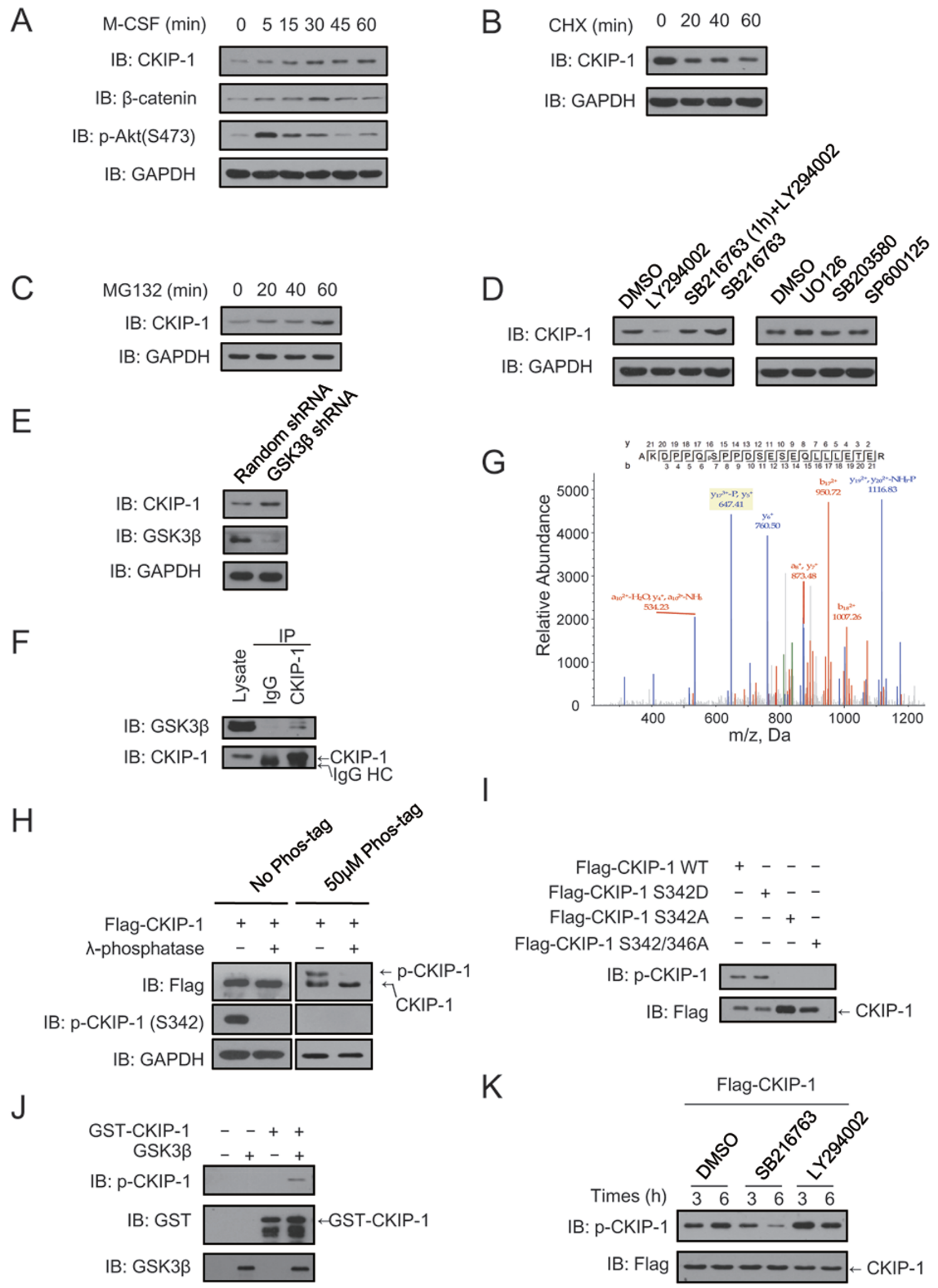


an important role in myelopoiesis in vivo [37], we performed a granulocyte/macrophage colony forming assay to determine whether the loss of CKIP-1 affected myelopoiesis. Granulocyte/macrophage colonies from BMCs of $C K I P-1^{-1-}$ mice showed no significant differences from that of their WT littermates, but $C K I P-1^{-1-}$ splenic cells generated more colonies than WT cells (Figure 8G). These data indicate a role of CKIP-1 in regulating tissue macrophage numbers and development of their precusors in vivo.

CKIP-1, Akt and GSK3 $\beta$ form a feedback loop in macrophage regulation

Based on our findings, we propose that CKIP-1 forms a negative feedback loop together with Akt and GSK3 $\beta$ to maintain the balance of initiation and termination of M-CSF signaling. In resting macrophages, CKIP-1 undergoes protein synthesis and constitutive proteasomal degradation driven by GSK $3 \beta$-mediated phosphorylation on Ser342, similar to the case of $\beta$-catenin [15]. In this manner, CKIP-1 was maintained at a low protein level (Figure 9, left). Upon M-CSF treatment, CSF$1 \mathrm{R}$ activates PI3K and Akt kinases, and the process involves TRAF6-mediated K63-linked ubiquitination of Akt followed by its plasma membrane recruitment. Akt inactivates GSK3 $\beta$ through phosphorylation, leading to reduced phosphorylation and thus ubiquitination of CKIP-1 and then accumulation of CKIP-1. Inactivation of GSK $3 \beta$ also causes the stabilization of $\beta$-catenin. $\beta$-catenin translocates from the cytoplasm to the nucleus to regulate expression of genes such as cyclin $D$ and $c$ $m y c$, promoting macrophage cell cycle progression [15]. Meanwhile, the accumulated CKIP-1 interacts with the TRAF6 ubiquitin ligase and inhibits TRAF6-mediated Akt ubiquitination. In this manner, CKIP-1 terminates
M-CSF-induced Akt activation and prevents excessive macrophage proliferation (Figure 9, right). Once Akt is inactivated, GSK3 $\beta$ activity is restored. This would trigger CKIP-1 phosphorylation, ubiquitination and degradation, thus returning CKIP-1 to a normal low level.

\section{Discussion}

Macrophages are found in all tissues of adult mammals, and most of them are regulated by M-CSF [7, 38]. $\mathrm{M}-\mathrm{CSF}$ is a pleiotropic macrophage growth factor, acting on not only fully differentiated macrophages but also their myeloid progenitors. Together with other growth factors such as IL-3 or alone, M-CSF can support myeloid linage cell proliferation and differentiation [7]. In particular, M-CSF synergizes with the receptor activator of NF- $\kappa \mathrm{B}$ ligand (RANKL) to regulate the differentiation of mononuclear precusors to osteoclasts [39]. Studies on M-CSF-deficient mice indicate that M-CSF is essential for regulating the survival, proliferation and differentiation of tissue macrophages [7, 40-42]. However, less is known about how the M-CSF signaling pathway is terminated. Our findings uncover CKIP-1 as an important negative regulator of macrophage proliferation and $\mathrm{M}$ CSF signaling, and delineate a molecular framework for CKIP-1 function in macrophages.

We showed that CKIP-1 inhibits TRAF6-mediated Akt activation to inhibit macrophage proliferation, revealing a role for TRAF6 in M-CSF signaling. We noted that previous reports did not implicate a role for TRAF6 in M-CSF signaling, despite that $T R A F \sigma^{\prime-}$ mice have severe osteopetrosis due to lack of mature osteoclasts reminiscent of M-CSF-deficient and CSF1-R-deficient mice [42-43], because TRAF6 plays a pivotal role in RANKL signaling, which is known to be essential for osteoclast

Figure 6 CKIP-1 is phosphorylated by GSK3 $\beta$ at Ser342. (A) BMDMs were starved of M-CSF for 4 h and restimulated with M-CSF $(50 \mathrm{ng} / \mathrm{ml})$ for various periods and harvested for IB analysis. (B) BMDMs were treated with the protein synthesis inhibitor $\mathrm{CHX}(20 \mu \mathrm{g} / \mathrm{ml})$ for various times and harvested for IB analysis. (C) BMDMs were treated with the proteasome inhibitor MG132 (20 $\mu \mathrm{M})$ and harvested for IB analysis. (D) BMDMs were treated with the PI3K inhibitor LY294002 (10 $\mu$ M), GSK3 $\beta$ inhibitor SB216763 $(10 \mu \mathrm{M})$, Erk inhibitor UO126 (10 $\mu \mathrm{M})$ or p38 inhibitor SB203580 $(10 \mu \mathrm{M})$ as indicated for $6 \mathrm{~h}$ (in certain case, preincubated with SB216763 for $1 \mathrm{~h}$ before LY294002 treatment) and harvested for IB analysis. (E) RAW264.7 cells were transfected with shRNA against GSK3 $\beta$ or a random shRNA. CKIP-1 and GSK3 $\beta$ expression was analyzed by IB. (F) RAW264.7 cells were collected for immunoprecipitation with CKIP-1 antibody, followed by IB analysis with GSK3ß antibody. (G) RAW264.7 cell lysates were immunoprecipitated with antibody against CKIP-1 for mass spectrometry. (H) Flag-CKIP-1 was transfected into 293T cells. The lysates were treated with $\lambda$-phosphatase or left untreated and then analyzed by either regular SDS-PAGE (lanes 1-2) or phos-tag-containing SDS-PAGE (lanes 3-4). (I) Flag-CKIP-1 or the indicated mutants were transfected into 293T cells. At $36 \mathrm{~h}$ post transfection, cells were harvested and the total lysates were blotted with the phosphoCKIP-1 antibody. (J) In vitro phosphorylation of CKIP-1 by GSK3 $\beta$. GST-CKIP-1 was expressed in bacteria, purified and then incubated with purchased active GSK3 $\beta$ kinase. Western blot analysis was performed with the phospho-CKIP-1 antibody. (K) Flag-CKIP-1 was transfected into 293T cells. At $24 \mathrm{~h}$ post transfection, cells were treated with the GSK3 inhibitor SB216763 (10 $\mu \mathrm{M})$ or PI3K inhibitor LY294002 $(20 \mu \mathrm{M})$ for indicated hours and harvested for IB analysis. 
A

Flag-CKIP-1 - + + + + +

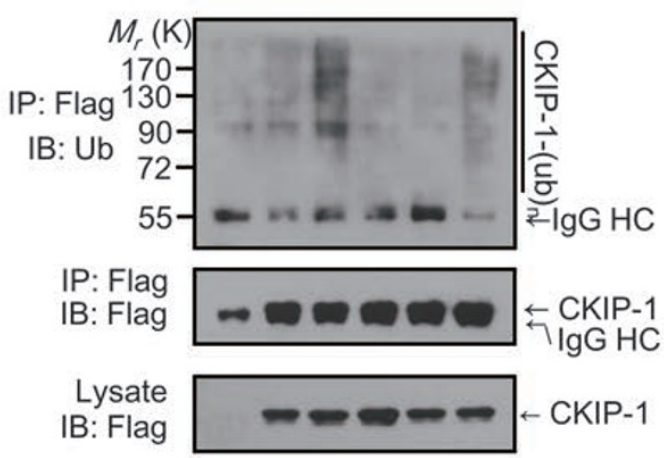

C
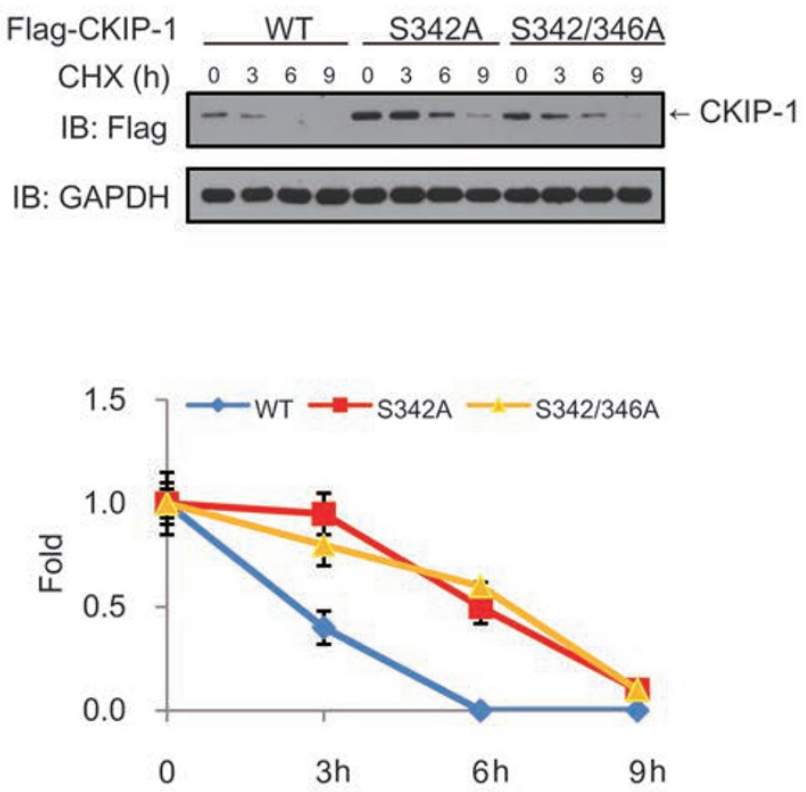

B

Flag-CKIP-1 WT - + -

Flag-CKIP-1 S342A - - +

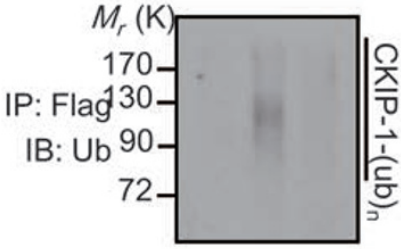

IP: Flag

IB: Flag

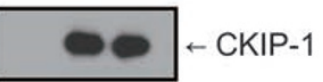

$\mathrm{D}$

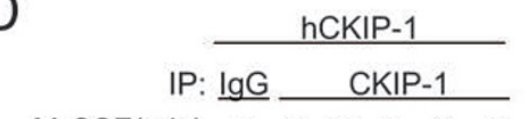

$\operatorname{M-CSF}(\min ) \quad 0 \quad 0 \quad 10 \quad 15 \quad 20 \quad 30$

IB:Ub

$M_{r}(\mathrm{~K})$
$170-$
$130-$
$90-$
$72-$

IB:CKIP-1

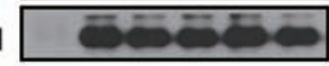

$\leftarrow$ CKIP-1

lysate
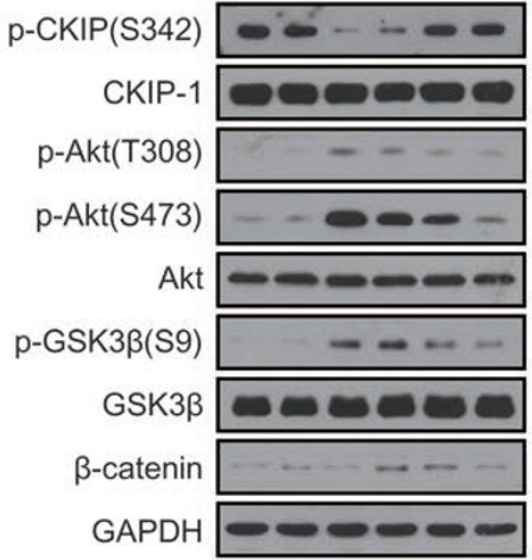

Figure 7 Phosphorylation of CKIP-1 by GSK3 $\beta$ triggers its ubiquitination and degradation. (A) Flag-CKIP-1 or empty vector were transfected into 293T cells. Twenty-four hours post transfection, cells were treated with MG132 (20 $\mu$ M), SB216763 (10 $\mu \mathrm{M})$, LiCl $(10 \mathrm{mM})$ or LY294002 $(20 \mu \mathrm{M})$ for $8 \mathrm{~h}$, then harvested for IP with Flag antibodies followed by ubiquitination assay. (B) Flag-CKIP-1 WT, Flag-CKIP-1 S342A or empty vectors were transfected into 293T cells. Thirty-six hours post transfection, cells were harvested and the total lysates were immunoprecipitated with Flag antibodies followed by ubiquitination assay. (C) 293T cells transfected with WT CKIP-1 or mutants were treated with $\mathrm{CHX}(50 \mu \mathrm{g} / \mathrm{ml})$ for the indicated periods and harvested for IB analysis. (D) RAW264.7 cells were infected with human CKIP-1 lentivirus, and serum-starved for $24 \mathrm{~h}$ and then restimulated with M-CSF $(50 \mathrm{ng} / \mathrm{ml})$ for various periods and harvested for IP and IB analysis.

differentiation and maturation [27, 44]. In contrast to RANKL signaling in which the role of TRAF6 has been extensively investigated in vivo and in vitro [28, 45-47], studies on its role in M-CSF signaling are rare. In an in vitro system using splenocytes to induce macrophages with M-CSF, $T R A F \sigma^{\prime-}$ splenocytes gave rise to almost an equal number of macrophage-like cells compared with wild type [44]. These data seemed to suggest that TRAF6 
was not involved in M-CSF signaling. Compared with BMCs, splenocytes have less potential to proliferate and differentiate to matured myeloid linage cells in response to M-CSF. Distinct from the generation from BMDMs, M-CSF-induced differentiation of splenocytes to macrophage-like cells is more likely the result of splenic monocyte differentiating into macrophages. In such a process, macrophages proliferate poorly. Thus, it is likely that the differentiation potential and the number of splenic monocytes are not affected by TRAF6 deficiency. Another study using TRAF6-deficient mice and BM chimeras reconstituted with TRAF6-deficient fetal liver cells showed that splenic dendritic cells (DC), especially the myeloid-related $\mathrm{CD} 8 \alpha^{-}$subpopulation[48-50], are dramatically decreased in $T R A F \sigma^{-1}$ mice and $T R A F \sigma^{-1} \mathrm{BM}$ chimeras [51], suggesting that TRAF6 is important for DC development. Since DC shares the same origin with macrophages and monocytes, and their development are also modulated by M-CSF [52-53], this report supports that TRAF6 plays a role in myeloid cell development and that it may be involved in M-CSF signaling. Considering the complexity of regulation by M-CSF, to further demonstrate the role of TRAF6 in M-CSF signaling, future studies are needed to examine tissue macrophage development (besides osteoclasts) using $T R A F \sigma^{\prime-}$ mice, $T R A F \sigma^{1-} \mathrm{BM}$ chimeras or inducible conditional knockout mice of TRAF6 and to investigate the role of TRAF6 in primary macrophages such as BMDMs.

We identified CKIP-1 as a novel substrate of GSK3 $\beta$ and the phosphorylation site located at serine 342. Additional results reveal that GSK $3 \beta$ inhibits CKIP-1 through phosphorylation followed by ubiquitination and proteasomal degradation. In resting macrophages, CKIP1 is a short-lived protein with a half-life of about one hour. During M-CSF stimulation, CKIP-1 protein levels are dynamically regulated accompanied by the fluctuating phosphorylation. We tried to identify the responsible ubiquitin ligase for CKIP-1 but did not succeed yet. Further investigations should be performed to fill this gap. To the best of knowledge, this is the first report of phosphorylation and ubiquitination of CKIP-1 protein.

GSK $3 \beta$ has been identified as the first direct target of Akt [54]. Akt phosphorylates GSK3 $\beta$, and inactivates the latter in response to a variety of signals, leading to diverse biological effects [11]. Previous studies showed that Akt and GSK3 $\beta$ are both phosphorylated downstream of M-CSF signaling and have a role in regulation of macrophage proliferation [8-9, 15], but the relationship between them under M-CSF signaling remains unveiled. Our results provided evidence that Akt contributes to GSK $3 \beta$ phosphorylation in M-CSF signaling. We also showed that GSK $3 \beta$ can regulate Akt activity by controlling CKIP-1 protein stability. These findings illustrate a feedback loop in the Akt-GSK3 $\beta$ axis. Further results indicate that this Akt-GSK3 $\beta$-CKIP-1 feedback loop is pivotal for the proper regulation of M-CSF signaling and macrophage homeostasis. Although, we have identified such a feedback loop in M-CSF signaling, it is possible that this might be a common mechanism in diverse signaling pathways.

Based on its ability to inhibit Akt, CKIP-1 has been suggested as a candidate tumor suppressor [29]. However, whether CKIP-1 is a bona fide Akt suppressor in vivo was still unclear. Our current study utilized the knockout mouse model to show that CKIP-1 is indeed a critical regulator of Akt signaling, at least in the context of macrophages. Moreover, the molecular mechanism by which CKIP-1 inhibits Akt activation was previously unknown. Although CKIP-1 binds to the PH domain of Akt, CKIP1 does not compete with Akt for phosphoinositide binding [29]. Our findings indicate that CKIP-1 interacts with TRAF6 and antagonizes its ligase activity towards Akt. These results provide new insights into the mechanism by which CKIP-1 regulates Akt and extends the physiological role of such regulation into the context of macrophage proliferation.

Our previous studies demonstrate that $C K I P-1^{-/-}$mice display a higher bone mass due to accelerated bone formation [21], as well as spontaneous cardiac hypertrophy associated with aging and hypersensitivity to pressure overload-induced pathological cardiac hypertrophy [22]. The present study provides the first in vivo evidence to indicate a physiological role of CKIP-1 in macrophage development. Studies exploring the functions of CKIP-1 in immune responses against challenges such as extrinsic pathogens are currently ongoing.

\section{Materials and Methods}

\section{Mouse, cells and reagents}

$C K I P-1^{-1-}$ mice on a $\mathrm{C} 57 \mathrm{BL} / 6$ background were prepared as previously described [21]. Mice were maintained and handled in accordance with protocols approved by Chinese Academy of Military Medicine Science. RAW264.7 cells were cultured in RPMI1640 medium with standard formulations, whereas 293T were cultured in DMEM. 32D cells were maintained in RPMI-1640 containing 5\% WEHI3-conditioned medium. 32D-CSF1R cell line was constructed by overexpression of the full-length CSF1-R into 32D cells mediated by a lentiviral system, followed by selection in M-CSF-containing, but IL-3-free, medium. The proteasome inhibitor MG-132, protein synthesis inhibitor CHX, PI3K inhibitors LY294002 and Wortmannin, GSK3 $\beta$ inhibitor SB216763, LPS (Salmonella minnesota Re595) were purchased from Sigma. Erk inhibitor UO126 and p38 inhibitor SB203580 were purchased from Santa Cruz. Phos-tag ${ }^{\text {TM }}$ AAL-107 was purchased from WakoChem. 

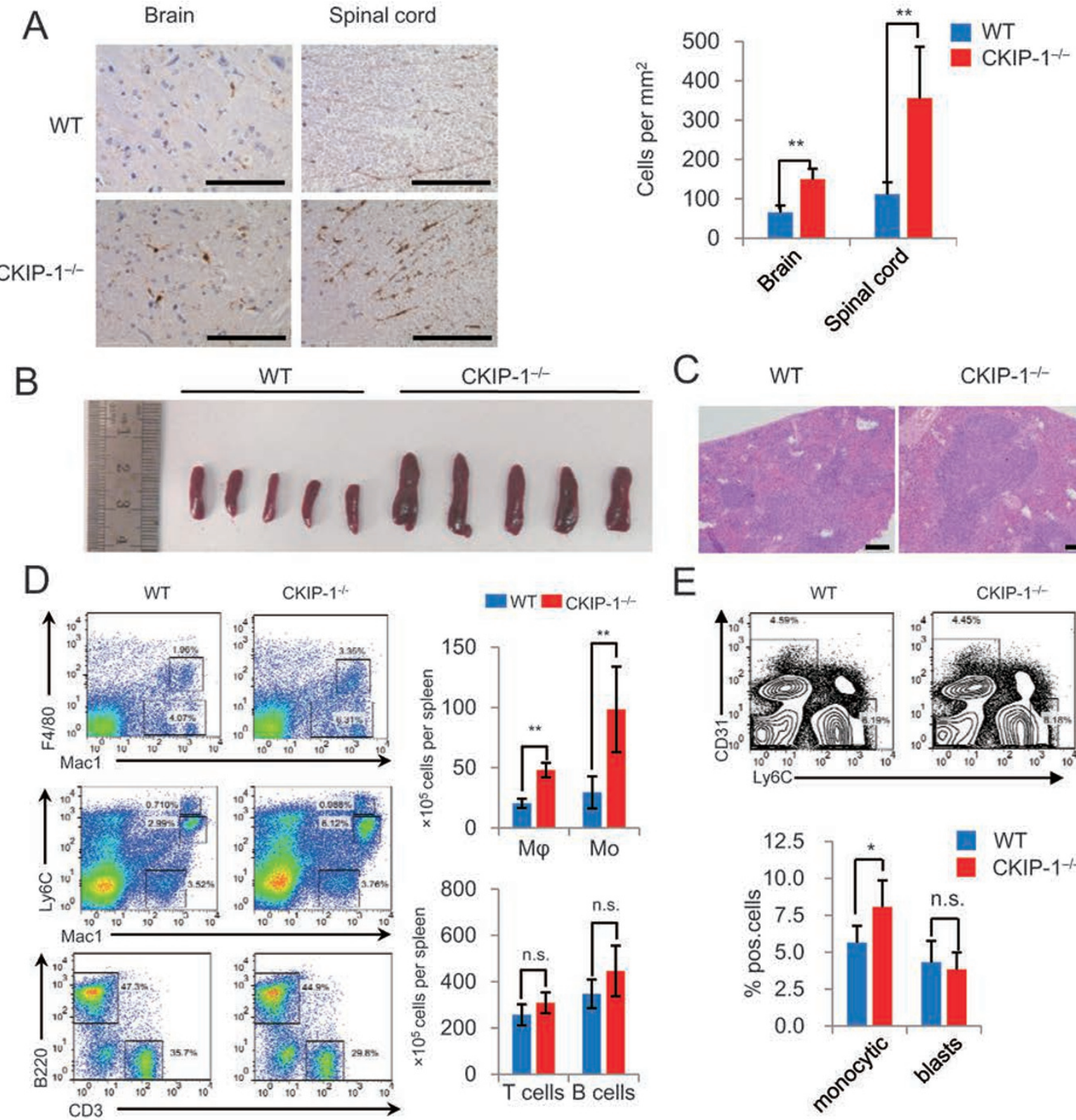

B
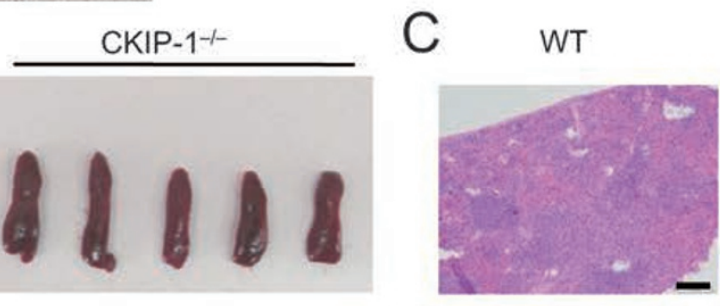

CKIP-1-1-

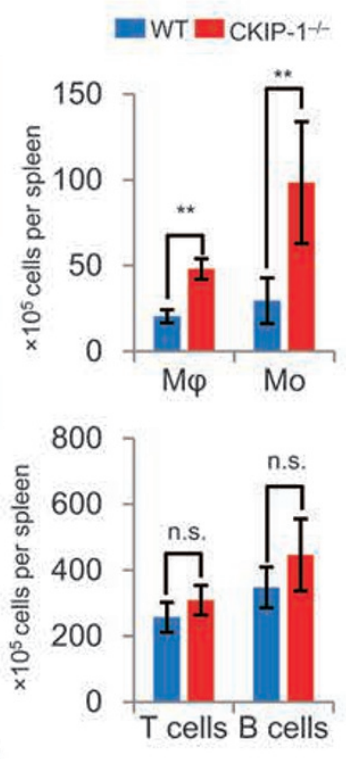

E

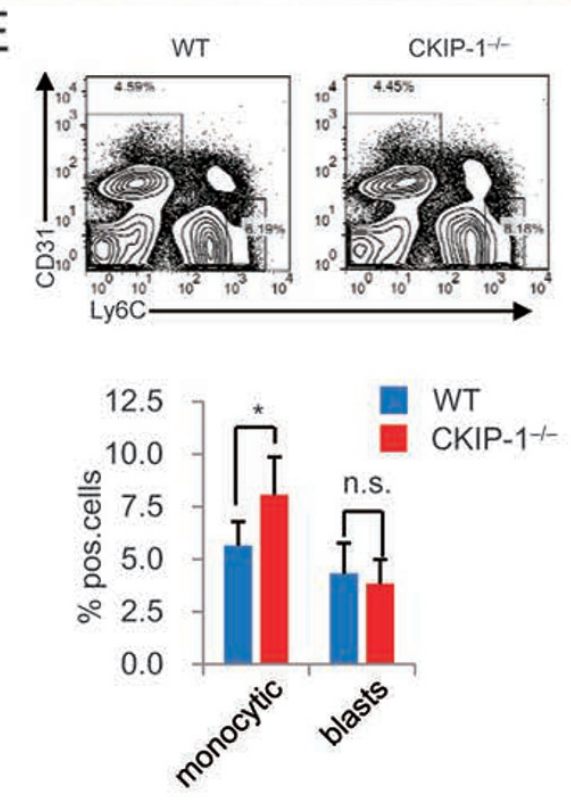

F
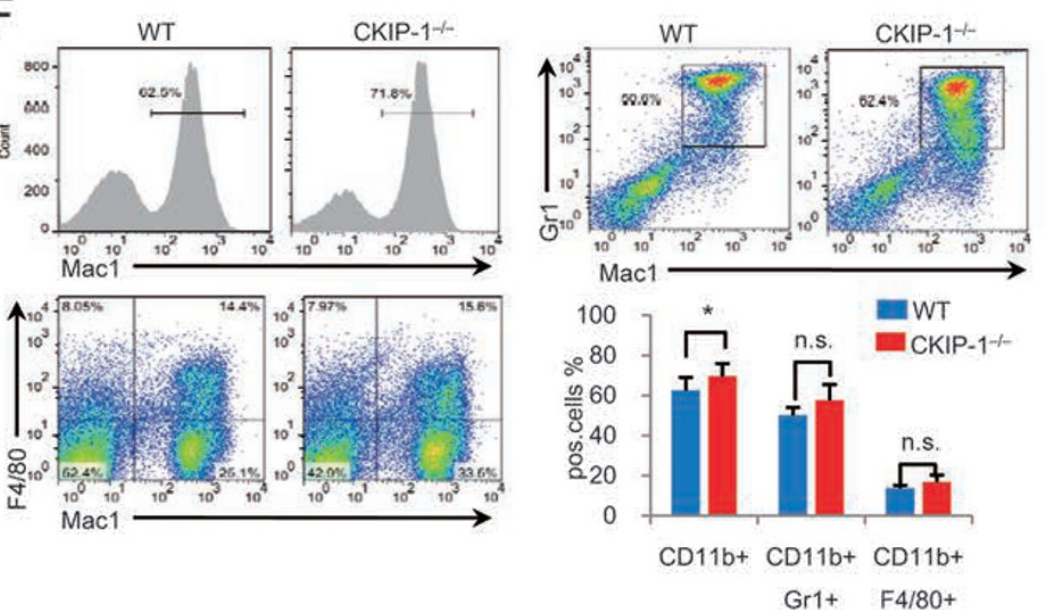

$G$

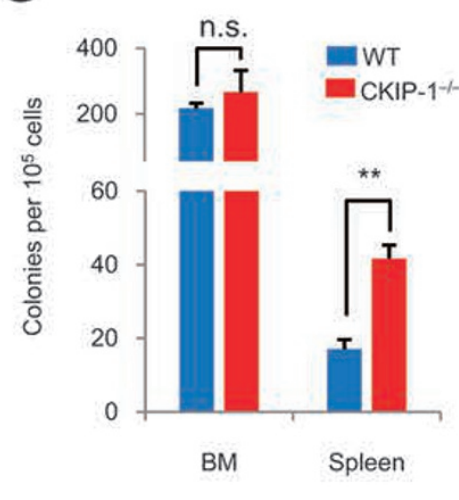


Mouse bone marrow-derived macrophages

Femur and tibia were harvested from mice, washed with PBS and BMCs were flushed out with PBS. The cell suspension was filtered through $70 \mu \mathrm{m}$ cell strainer to remove any cell clumps. The single cell suspension was then cultured in RPMI-1640 medium containing $10 \%$ (vol/vol) fetal calf serum (FCS), M-CSF (20 ng/ $\mathrm{ml}$; R\&D). In some experiments, L929 condition media (LCM) was used as a source of M-CSF as indicated. To fully differentiate BMDM, the cells were cultured for 7 days with fresh media changed every other day. The generated BMDMs are $\mathrm{CD}_{11} \mathrm{~b}^{+}$and $\mathrm{F} 4 / 80^{+}$(purity $>95 \%$ ).

\section{Transfection and viral infection}

Transient transfections were performed with Lipofectamine ${ }^{\mathrm{TM}}$ 2000 transfection reagent (Invitrogen) following the manufacturer's instructions. Human and mouse CKIP-1 and mouse CSF1-R cDNAs were inserted into murine stem cell virus (MSCV)-IRESGFP or (MSCV)-IRES-Puro vector for overexpression assay, CKIP-1, TRAF6 and p65 shRNAs were inserted into U6-PuroGFP vector for knockdown assays. CKIP-1 and CSF1-R-lentiviral vectors, CKIP-1-lentiviral shRNA (5'-CCTGAGTGACTATGAGAAG-3'), TRAF6-lentivivral shRNA\#1 (5'-GCCCAGGCTGTTCATAATGTT-3'), shRNA\#2 (5'-CCTGTGAATTTCAGAGGCT-3'), p65-lentivivral shRNA\#1 (5'-AGGCCATATAGCCTTACTATC-3'), shRNA\#2 (5'-GGAGTACCCTGAAGCTATAAC-3') and random shRNA (5'-TTCTCCGAACGTGTCACGT-3') were transfected with packing plasmids into $293 \mathrm{~T}$ cells for 2 days, and virus particles were used to infect 32D-CSF1R or RAW264.7 cells as indicated. Selections were carried out if necessary by culturing in medium containing $2 \mu \mathrm{g} / \mathrm{ml}$ puromycin for 2 days.

\section{CKIP-1-phospho-Ser342 polyclonal antibody}

CKIP-1-phospho-Ser342 polyclonal antibody was raised against the phospho-peptide rkakdpprspppdsc of human CKIP-1.

\section{Flow cytometry and antibodies}

F4/80 (BM8), CD115(AFS98), CD19 (1D3), CD284 (UT41), CD31 (390), CD3 (145-2C-11), B220 (RA3-6B2), CD11b (M1/70), I-A $^{\mathrm{b}}$ (AF6-120.1), Ly6C (AL-21) antibodies were from eBioscience or BD Pharmigen. FACS analyses were done on FACSCalibur (BD Biosciences). Cell sorting was conducted on FACSAria (BD Biosciences). Dead cells (DAPI positive) were excluded from sorting. Data were analyzed with the FlowJo software (Treestar).

\section{Histology}

WT and CKIP-1-deficient mice were killed at 10-12 weeks after birth. Tissues were fixed $24 \mathrm{~h}$ in $10 \%$ neutral-buffered formalin and then embedded in paraffin. Sections $(4 \mu \mathrm{m})$ in thickness were cut and stained for histological examination. Immunohistochemistry was used to investigate microglia distribution. Polyclonal rabbit primary antibody to Iba-1 (1:1 000 dilution; 019-19741; WakoChem) was diluted in PBS with $1 \%$ (wt/vol) BSA. Images were obtained with a Nikon DP70 camera mounted on a Nikon Bx60 microscope with Cell-F imaging software (Soft Imaging System).

\section{Proliferation assay}

M-CSF-stimulated cells were labeled for indicated time with BrdU (5-bromodeoxyuridine; $10 \mu \mathrm{M}$ ) and incorporation was measured by flow cytometry with a BrdU Flow kit (BD Pharmingen) according to the manufacturer's instructions.

\section{Analysis of cell cycle and apoptosis}

Cell cycle and cell death status were determined on the basis of the DNA content of cells. Cells were washed with flow cytometry buffer (2\% (vol/vol) FCS in PBS), fixed with $70 \%$ ethanol and stained with propidium iodide (Sigma) according to established protocols. Samples were analyzed on a FACSCalibur (BD Biosciences). Data were analyzed with the FlowJo software (Treestar).

\section{Immunoprecipitation (IP), immunoblotting (IB),} immunofluorescence (IF) and ubiquitination assays

IP, IB, IF and ubiquitination assays were carried out as previously described [21]. The following antibodies were used for IP, IB and IF. Anti-TRAF6, Akt, ubiquitin, CKIP-1, phospho (S276)p65 and GAPDH antibodies were purchased from Santa Cruz. Anti-phospho (S473)-Akt, phospho (T308)-Akt, phospho-Erk, Erk, phospho-p38, p38, phospho (S9)-GSK3 $\beta$, GSK3 $\beta$, $\beta$-catenin, $\mathrm{IKK} \alpha / \beta, \mathrm{p}-\mathrm{IKK} \alpha / \beta, \mathrm{I} \kappa \mathrm{B}$ and $\mathrm{p} 65$ antibodies were from Cell Signaling Technology. Anti-Myc antibody was from MBL. Anti-HA antibody was from Roche. Anti- $\alpha$-tubulin and anti-Flag antibodies were from Sigma.

\section{GST pull-down assays}

Recombinant GST-CKIP-1 fusion proteins were expressed in bacteria and purified using glutathione-Sepharose. The MycTRAF6 was expressed in 293T cells. Subsequently, the GST-pulldown assays were carried out by incubating GST-CKIP-1-bound

Figure 8 Macrophage expansion in CKIP-1-deficient mice. (A) Immunohistochemical analysis of IBA-1 (brown), a microglia marker, in brain and spinal cord of WT and CKIP-1-deficient mice $(n=3$ per group; original magnification, $\times 400$. Scale bar, 50 $\mu \mathrm{m})$. (B) Photographs of spleens of 4-5-month-old WT and CKIP-1 $1^{-1-}$ mice. (C) Representative hematoxylin-eosin (HE) staining of spleens sections from B. (Original magnification, $\times 100$. Scale bar, $100 \mu \mathrm{m}$ ). (D) Flow cytometry of splenocytes of WT and CKIP-1 $1^{-1-}$ mice ( $n=5$ per group). Macrophages were identified as Mac $1^{+} \mathrm{F} 4 / 80^{+}, \mathrm{Ly}_{6 \mathrm{C}} \mathrm{int}^{\mathrm{in}} \mathrm{Mac} 1^{+}$cells corresponding to resident monocytes and $\mathrm{Ly} 6 \mathrm{C}^{\text {hi }}$ Mac ${ }^{+}$cells representing inflammatory monocytes. Numbers indicate the percentages of cells in the squares. (E, F) Representative FACS profiles and average percentage of immature myeloid cells from bone marrow $(n=$ 6). (E) Ly6 $C^{\text {hi }} / C D 31^{\text {low }}$ population represents monocytic cells and CD31 hi/Ly6C- population represents common blasts. Statistical analysis results are shown in the lower panal. (F) Representative FACS profiles of myeloid cell populations in Mac-1/Gr-1 and Mac-1/F4/80 FACS profiles from bone marrow. Numbers indicate the percentages of cells in the indicated gates. Statistical results were shown in the lower panal. (G) Total BMCs and splenocytes were harvested and cultured onto methylcellulose medium. G/M colonies were enumerated 8 days after plating. ${ }^{*} P<0.05$, ${ }^{* *} P<0.01$ (Student's $t$-test); n.s., no significant difference (mean $\pm \mathrm{SD}$ ). Data are representative of three independent experiments. 

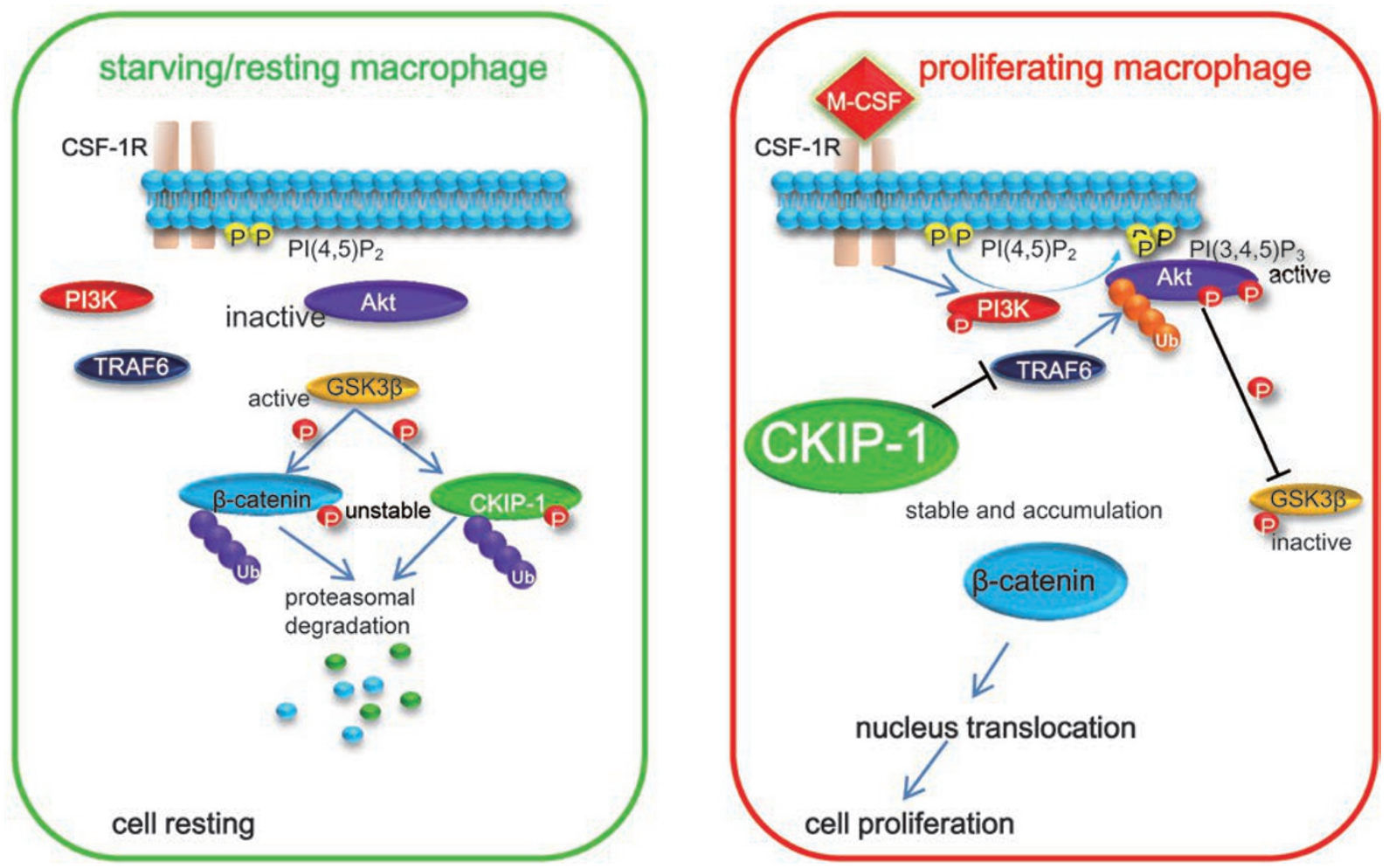

Figure 9 The proposed working model of CKIP-1 with Akt and GSK3 $\beta$ in regulating the macrophage proliferation and M-CSF signaling.

beads with Myc-TRAF6-expressing $293 \mathrm{~T}$ cell lysates at $4{ }^{\circ} \mathrm{C}$ for 8 $\mathrm{h}$. The beads were washed and the bound proteins were analyzed by SDS-PAGE and IB analysis.

\section{In vitro phosphorylation}

Recombinant GST-CKIP-1 fusion proteins were expressed in bacteria and purified using glutathione-sepharose. Purified GSTCKIP-1 proteins were left bound on beads. The beads were washed three times with kinase reaction buffer $(20 \mathrm{mM}$ Tris- $\mathrm{HCl}, \mathrm{pH} 7.5$, $10 \mathrm{mM} \mathrm{MgCl}_{2}$ and $5 \mathrm{mM}$ DTT). In vitro phosphorylation reactions were carried out by combining $20 \mu \mathrm{l}$ of glutathione-sepharosebound GST-CKIP-1 in $5 \mu$ l of kinase reaction buffer containing ATP $(200 \mu \mathrm{M})$ and active GSK-3 $\beta$ (10 U per reaction, NEB). The samples in a total volume of $50 \mu \mathrm{l}$ were incubated at $30^{\circ} \mathrm{C}$ for 30 $\mathrm{min}$, and the reactions were terminated by addition of SDS sample buffer. The phosphorylated proteins were separated by SDS-PAGE and IB analysis.

\section{Granulocyte/macrophage CFU assay}

Single-cell suspensions were prepared from spleen and bone marrow. To detect G/M colony-forming ability, MethoCult 3534 (Stem cell Technology) containing IL-3, IL-6 and stem cell factor (SCF) were used to culture cells of interests. In all, $2 \times 10^{4} \mathrm{BMCs}$ and $2 \times 10^{5}$ splenocytes were plated to each plate. After 8 days of culture, the formation of colonies was observed and enumerated under microscope.

\section{Membrane fractionation}

www.cell-research.com | Cell Research
RAW264.7 cells were serum-starved for $24 \mathrm{~h}$ in DMEM containing $0.1 \% \mathrm{FBS}$, and then stimulated with M-CSF (50 ng/ml) for various periods and cytosolic and membrane fractions were prepared using the ProteoJET ${ }^{\mathrm{TM}}$ Membrane Protein Extraction kit (Fermentas) according to the manufacturers' standard procedures.

\section{Site-directed mutagenesis}

Site-directed mutagenesis of Flag-CKIP-1 (S342A and S342/346A) was performed using the QuikChange Site-Directed Mutagenesis kit (Stratagene) according to the manufacturer's instructions.

\section{CHX chase assays}

CHX chase assays were performed as described previously [21]. Cells were treated with CHX $(20 \mu \mathrm{g} / \mathrm{ml})$ for various times 2 days after transfections. Cells were lysed and analyzed by immunoblotting.

\section{Quantitative PCR analysis}

Total RNA was isolated with TRIzol (Invitrogen), and reverse transcription was performed with ReverTra Ace (Toyobo) according to the manufacturer's instructions. For quantitative PCR, cDNA fragments were amplified by Realtime PCR Master Mix (Toyobo); fluorescence for each gene was detected by an iQ5 real-time PCR system (Bio-rad). The mRNA expression level of each gene was normalized to the expression level of GAPDH. The primers used were as following: c-Myc F: 5'-AATCCTGTACCTCGTCCGAT-3', R: 5'-TCTTCTCCACAGACAC- 
CACA-3'; cyclin D1 F: 5'-TGCTACCGCACAACGCA-3', R: 5'-TCAATCTGTTCCTGGCAGGC-3'; cyclin D2 F: 5'-CGTGTGATGCCCTGACTGAG-3', R: 5'-GACTTGGATCCGGCGTTATG-3'; CKIP-1 F: 5'- AATTCTGCGGGAAAGGGATTT-3', R: 5'-AACACCTCCTGACTGTTTTCTC-3'; GAPDH F: 5'-AGGTCGGTGTGAACGGATTTG-3', R: 5'-TGTAGACCATGTAGTTGAGGTCA-3'.

\section{Statistics}

Statistical significance was calculated with the two-tailed Student's $t$-test.

\section{Acknowledgments}

We thank Drs Jiang Peng for RAW264.7 cell line, Changyan Li for lentiviral transduction, Hongbing Shu for TARF6 plasmid, Jiyan Zhang for BMDM cultures. This work was supported by Chinese National Basic Research Programs (2011CB910802, 2012CB910304), the National Key Technologies R\&D Program for New Drugs (2014ZX09J14106-04C), Chinese National Natural Science Foundation Projects (31125010, 31270912 and 81221004) and a grant from State Key Laboratory of Proteomics (SKLPK201102).

\section{References}

1 Martinez FO, Helming L, Gordon S. Alternative activation of macrophages: an immunologic functional perspective. Annu Rev Immunol 2009; 27:451-483.

2 Hamilton JA. Colony-stimulating factors in inflammation and autoimmunity. Nat Rev Immunol 2008; 8:533-544.

3 Chitu V, Stanley ER. Colony-stimulating factor-1 in immunity and inflammation. Curr Opin Immunol 2006; 18:39-48.

4 Stanley ER, Berg KL, Einstein DB, et al. Biology and action of colony-stimulating factor-1. Mol Reprod Dev 1997; 46:410.

5 Wiktor-Jedrzejczak W, Ratajczak MZ, Ptasznik A, Sell KW, Ahmed-Ansari A, Ostertag W. CSF-1 deficiency in the op/op mouse has differential effects on macrophage populations and differentiation stages. Exp Hematol 1992; 20:1004-1010.

6 Hamilton JA. CSF-1 signal transduction. J Leukoc Biol 1997; 62:145-155.

7 Pixley FJ, Stanley ER. CSF-1 regulation of the wandering macrophage: complexity in action. Trends Cell Biol 2004; 14:628-638

8 Lee AW, States DJ. Colony-stimulating factor-1 requires PI3kinase-mediated metabolism for proliferation and survival in myeloid cells. Cell Death Differ 2006; 13:1900-1914.

9 Smith JL, Schaffner AE, Hofmeister JK, et al. ets-2 is a target for an akt (protein kinase B)/jun N-terminal kinase signaling pathway in macrophages of motheaten-viable mutant mice. Mol Cell Biol 2000; 20:8026-8034.

10 Lee AW. Synergistic activation of mitogen-activated protein kinase by cyclic AMP and myeloid growth factors opposes cyclic AMP's growth-inhibitory effects. Blood 1999; 93:537553.

11 Manning BD, Cantley LC. AKT/PKB signaling: navigating downstream. Cell 2007; 129:1261-1274.
12 Varticovski L, Druker B, Morrison D, Cantley L, Roberts T. The colony stimulating factor- 1 receptor associates with and activates phosphatidylinositol-3 kinase. Nature 1989; 342:699-702.

13 Datta SR, Brunet A, Greenberg ME. Cellular survival: a play in three Akts. Genes Dev 1999; 13:2905-2927.

14 Sampaio NG, Yu W, Cox D, et al. Phosphorylation of CSF-1R Y721 mediates its association with PI3K to regulate macrophage motility and enhancement of tumor cell invasion. J Cell Sci 2011; 124:2021-2031.

15 Otero K, Turnbull IR, Poliani PL, et al. Macrophage colonystimulating factor induces the proliferation and survival of macrophages via a pathway involving DAP12 and betacatenin. Nat Immunol 2009; 10:734-743.

16 Zhang L, Xing G, Tie Y, et al. Role for the pleckstrin homology domain-containing protein CKIP-1 in AP-1 regulation and apoptosis. EMBO J 2005; 24:766-778.

17 Bosc DG, Graham KC, Saulnier RB, et al. Identification and characterization of CKIP-1, a novel pleckstrin homology domain-containing protein that interacts with protein kinase CK2. J Biol Chem 2000; 275:14295-14306.

18 Safi A, Vandromme M, Caussanel S, et al. Role for the pleckstrin homology domain-containing protein CKIP-1 in phosphatidylinositol 3-kinase-regulated muscle differentiation. Mol Cell Biol 2004; 24:1245-1255.

19 Canton DA, Olsten ME, Kim K, et al. The pleckstrin homology domain-containing protein CKIP-1 is involved in regulation of cell morphology and the actin cytoskeleton and interaction with actin capping protein. Mol Cell Biol 2005; 25:3519-3534.

20 Nie J, Liu L, He F, Fu X, Han W, Zhang L. CKIP-1: a scaffold protein and potential therapeutic target integrating multiple signaling pathways and physiological functions. Ageing Res Rev 2013; 12:276-281.

21 Lu K, Yin X, Weng T, et al. Targeting WW domains linker of HECT-type ubiquitin ligase Smurf1 for activation by CKIP-1. Nat Cell Biol 2008; 10:994-1002.

22 Ling S, Sun Q, Li Y, et al. CKIP-1 inhibits cardiac hypertrophy by regulating class II histone deacetylase phosphorylation through recruiting PP2A. Circulation 2012; 126:3028-3040.

23 Zhang L, Tang Y, Tie Y, et al. The PH domain containing protein CKIP-1 binds to IFP35 and Nmi and is involved in cytokine signaling. Cell Signal 2007; 19:932-944.

24 Juhasz K, Zvara A, Lipp AM, et al. Casein kinase 2-interacting protein-1, an inflammatory signaling molecule interferes with TNF reverse signaling in human model cells. Immunol Lett 2013; 152:55-64.

25 Klappacher GW, Lunyak VV, Sykes DB, et al. An induced Ets repressor complex regulates growth arrest during terminal macrophage differentiation. Cell 2002; 109:169-180.

26 Yang WL, Wang J, Chan $\mathrm{CH}$, et al. The E3 ligase TRAF6 regulates Akt ubiquitination and activation. Science 2009; 325:1134-1138.

27 Lomaga MA, Yeh WC, Sarosi I, et al. TRAF6 deficiency results in osteopetrosis and defective interleukin-1, CD40, and LPS signaling. Genes Dev 1999; 13:1015-1024.

28 Kobayashi N, Kadono Y, Naito A, et al. Segregation of TRAF6-mediated signaling pathways clarifies its role in osteoclastogenesis. EMBO J 2001; 20:1271-1280. 
29 Tokuda E, Fujita N, Oh-hara T, et al. Casein kinase 2-interacting protein-1, a novel Akt pleckstrin homology domaininteracting protein, down-regulates PI3K/Akt signaling and suppresses tumor growth in vivo. Cancer Res 2007; 67:96669676.

30 Wang Y, Tang Y, Teng L, Wu Y, Zhao X, Pei G. Association of beta-arrestin and TRAF6 negatively regulates toll-like receptor-interleukin 1 receptor signaling. Nat Immunol 2006; 7:139-147.

31 Vallabhapurapu S, Karin M. Regulation and function of NFkappaB transcription factors in the immune system. Annu Rev Immunol 2009; 27:693-733.

32 Pagliari LJ, Perlman H, Liu H, Pope RM. Macrophages require constitutive NF-kappaB activation to maintain A1 expression and mitochondrial homeostasis. Mol Cell Biol 2000; 20:8855-8865.

33 Wang Y, Mo X, Piper MG, et al. M-CSF induces monocyte survival by activating NF-kappaB p65 phosphorylation at Ser276 via protein kinase C. PLoS One 2011; 6:e28081.

34 Lee AW. The role of atypical protein kinase C in CSF-1-dependent Erk activation and proliferation in myeloid progenitors and macrophages. PLoS One 2011; 6:e25580.

35 Frankenberger M, Pforte A, Sternsdorf T, Passlick B, Baeuerle PA, Ziegler-Heitbrock HW. Constitutive nuclear NF-kappa $\mathrm{B}$ in cells of the monocyte lineage. Biochem $J$ 1994; 304 (Part 1):87-94.

36 Kuo AH, Stoica GE, Riegel AT, Wellstein A. Recruitment of insulin receptor substrate-1 and activation of NF-kappaB essential for midkine growth signaling through anaplastic lymphoma kinase. Oncogene 2007; 26:859-869.

37 Simoncic PD, Bourdeau A, Lee-Loy A, et al. T-cell protein tyrosine phosphatase (Tcptp) is a negative regulator of colonystimulating factor 1 signaling and macrophage differentiation. Mol Cell Biol 2006; 26:4149-4160.

38 Wynn TA, Chawla A, Pollard JW. Macrophage biology in development, homeostasis and disease. Nature 2013; 496:445455.

39 Teitelbaum SL, Ross FP. Genetic regulation of osteoclast development and function. Nat Rev Genet 2003; 4:638-649.

40 Cecchini MG, Dominguez MG, Mocci S, et al. Role of colony stimulating factor-1 in the establishment and regulation of tissue macrophages during postnatal development of the mouse. Development 1994; 120:1357-1372.

41 Ryan GR, Dai XM, Dominguez MG, et al. Rescue of the colony-stimulating factor 1 (CSF-1)-nullizygous mouse (Csf1(op)/Csf1(op)) phenotype with a CSF-1 transgene and identification of sites of local CSF-1 synthesis. Blood 2001;
98:74-84.

42 Yoshida H, Hayashi S, Kunisada T, et al. The murine mutation osteopetrosis is in the coding region of the macrophage colony stimulating factor gene. Nature 1990; 345:442-444.

43 Dai XM, Ryan GR, Hapel AJ, et al. Targeted disruption of the mouse colony-stimulating factor 1 receptor gene results in osteopetrosis, mononuclear phagocyte deficiency, increased primitive progenitor cell frequencies, and reproductive defects. Blood 2002; 99:111-120.

44 Naito A, Azuma S, Tanaka S, et al. Severe osteopetrosis, defective interleukin-1 signalling and lymph node organogenesis in TRAF6-deficient mice. Genes Cells 1999; 4:353-362.

45 Lamothe B, Webster WK, Gopinathan A, Besse A, Campos AD, Darnay BG. TRAF6 ubiquitin ligase is essential for RANKL signaling and osteoclast differentiation. Biochem Biophys Res Commun 2007; 359:1044-1049.

46 Armstrong AP, Tometsko ME, Glaccum M, Sutherland CL, Cosman D, Dougall WC. A RANK/TRAF6-dependent signal transduction pathway is essential for osteoclast cytoskeletal organization and resorptive function. J Biol Chem 2002; 277:44347-44356.

47 Bai S, Kitaura H, Zhao H, et al. FHL2 inhibits the activated osteoclast in a TRAF6-dependent manner. J Clin Invest 2005; 115:2742-2751.

48 Vremec D, Shortman K. Dendritic cell subtypes in mouse lymphoid organs: cross-correlation of surface markers, changes with incubation, and differences among thymus, spleen, and lymph nodes. J Immunol 1997; 159:565-573.

49 Shortman K, Caux C. Dendritic cell development: multiple pathways to nature's adjuvants. Stem Cells 1997; 15:409-419.

50 Vremec D, Pooley J, Hochrein H, Wu L, Shortman K. CD4 and CD8 expression by dendritic cell subtypes in mouse thymus and spleen. J Immunol 2000; 164:2978-2986.

51 Kobayashi T, Walsh PT, Walsh MC, et al. TRAF6 is a critical factor for dendritic cell maturation and development. Immunity 2003; 19:353-363.

52 MacDonald KP, Rowe V, Bofinger HM, et al. The colonystimulating factor 1 receptor is expressed on dendritic cells during differentiation and regulates their expansion. $J$ Immunol 2005; 175:1399-1405.

53 Chow A, Brown BD, Merad M. Studying the mononuclear phagocyte system in the molecular age. Nat Rev Immunol 2011; 11:788-798.

54 Cross DA, Alessi DR, Cohen P, Andjelkovich M, Hemmings BA. Inhibition of glycogen synthase kinase- 3 by insulin mediated by protein kinase B. Nature 1995; 378:785-789.

(Supplementary information is linked to the online version of the paper on the Cell Research website.) 